\title{
EL DERECHO ADMINISTRATIVO EN TIEMPOS DE TRANSFORMACIONES
}

\author{
ADMINISTRATIVE LAW IN TIMES OF TRANSFORMATIONS
}

CRISTIAN MONTERO CARTES*

\section{RESUMEN}

Con ocasión de la exposición del planteamiento que afirma que el Derecho administrativo debe operar como ciencia que aspira a dirigir con eficacia los procesos sociales, el autor analiza tres temas específicos: 1) el procedimiento administrativo y la pluralidad de valores e intereses; 2) los retos que los progresos científico-tecnológicos le imponen al Derecho; y, 3) la construcción del Estado garante y regulador.

Palabras clave: Derecho administrativo, Procedimiento administrativo, Ciencia administrativa, Innovación y derecho, Estado garante y regulatorio, Interés general.

\section{ABSTRACT}

On the occasion of the presentation of the statement that administrative law should operate as a science that aims to effectively manage social processes,

* Abogado. Licenciado en Ciencias Jurídicas y Sociales por la Universidad de Concepción, Chile; Magíster en Derecho Público, Pontificia Universidad Católica de Valparaíso, Chile; Máster en Derecho Público, Universidad Carlos III de Madrid, España. Correo electrónico: crmontero@udec.cl.

Una versión preliminar de este trabajo fue presentada en la VI Conferencia Anual de ICON-S (International Society of Public Law): Public Law in times of change?, realizada durante los días 1, 2 y 3 de julio de 2019, en la Pontificia Universidad Católica de Chile, Santiago.

Artículo recibido para evaluación el 4 de agosto de 2019, y aprobado para su publicación el 22 de noviembre de 2019. 
the author analyzes three specific topics: 1) the administrative procedure and the plurality of values and interests; 2) the challenges that scientifictechnological progress imposes on the Law; and, 3) the construction of the guarantor and regulatory State.

Keywords: Administrative law, Administrative procedure, Administrative science, Innovation and law, Guarantor and regulatory State, Public interest.

\section{INTRODUCCIÓN}

En tanto instrumento que pretende regular la vida social, el Derecho y su aplicación se orienta a la consecución de determinados objetivos o valores, los que, en último término (tal como ha puesto de relieve W. HoffMANN-Riem), apuntan a resolver los problemas sociales, para lo cual debe considerarse, entre otros aspectos, la concreción de disposiciones valorativas y las consecuencias que derivan de las decisiones normativas. ${ }^{1}$

Desde tal perspectiva, se entiende que se denuncie por la teoría general del Derecho ${ }^{2}$ la desconexión que existe entre las tradicionales formulaciones teóricas (cuyo presupuesto es la existencia de un orden normativo racionalformal erigido sobre un conjunto de reglas destinadas a garantizar negativamente la libertad de los individuos de una comunidad y, por lo mismo, excluyente de otros sistemas normativos) y la realidad que ellas persiguen describir y explicar ${ }^{3}$ (en la cual se advierte que operan e interactúan una creciente pluralidad de sistemas jurídicos, caracterizados por su pretensión de perseguir la consecución de determinados fines u objetivos, a través de la disciplina positiva de la conducta de los agentes sociales). ${ }^{4}$ Como advierte CAlvo García, los presupuestos de la teoría clásica del Derecho no responden

${ }^{1}$ Hoffmann-Riem, Wolfgang, "Jurisdicción. El procesamiento judicial de la incertidumbre sobre los desarrollos futuros”, en Alguacil González-Aurioles, J.; Gutiérrez, I. (eds.), Constitución: norma y realidad. Teoría constitucional para Antonio López Pina, Marcial Pons, Madrid, 2014, p. 193.

2 Estas ideas se toman de (siguiendo a) Calvo García, Manuel, "Transformaciones jurídicas y teoría del derecho", Anuario de Filosofía de Derecho, 2012, núm. 28, pp. 35 y ss.

3 "La teoría del derecho ha tomado un rumbo que solo puede terminar en una creciente divergencia entre el fenómeno que analiza y la experiencia de los ciudadanos ordinarios." SOPER, Philip, Una teoría del Derecho (traducción por CARACciolo, Ricardo), Centro de Estudios Constitucionales, Madrid, 1993, p. 13.

4 Vid. Twining, William, “Teoría General del Derecho", Anales de la Cátedra Francisco Suárez, 2005, Vol. 39, pp. 612 y ss. 
a las realidades jurídicas "hacia las que abocan las transformaciones del derecho o que han encontrado un reconocimiento social como derecho". 5

En este orden de ideas, baste recordar que la asunción de que los postulados tradicionales a partir de los cuales se erigió el edificio del Estado liberal de Derecho están en crisis y, por lo mismo, en permanente cuestionamiento, es una aseveración que no requiere mayor explicación. Pues, más allá de sus causas, desde las ciencias sociales se viene apuntando que las sociedades industriales del siglo XIX se han transformado profundamente, lo cual explica que los paradigmas tradicionales del Estado liberal de Derecho - construidos en torno aquéllas- no logren explicar y fundamentar las realidades creadas por las sociedades modernas.

Justamente, entre las consecuencias que de ello derivan se aprecia el progresivo cuestionamiento de la capacidad del Derecho para ejercer su función de dirección y control. ${ }^{6}$ De aquí resulta, entonces, la imposibilidad de seguir operando únicamente - $\mathrm{O}$ cuando menos, no en forma central-con las clásicas construcciones teórico-dogmáticas, en razón de su insuficiencia por sí solas para explicar y orientar los nuevos paradigmas.

Lo anterior, sin embargo, no significa que deban abandonarse sin más, ni reemplazarse por entero las clásicas construcciones jurídicas, pues como anota ZAGREBelsky, el "rasgo más notorio del Derecho Público actual no es la sustitución radical de las categorías tradicionales, sino su 'pérdida de la posición central"'.?

En el contexto apuntado, el objetivo del presente trabajo es, con ocasión de la descripción del planteamiento que afirma que la ciencia administrativa debe operar como ciencia directiva,${ }^{8}$ puntualizar diversas modificaciones en

\footnotetext{
5 Calvo García, cit. (n. 2), pp. 36 y 42.

6 Sobre este extremo, vid., Parejo Alfonso, Luciano, Transformación y ¿reforma? del Derecho Administrativo en España, Instituto Nacional de Administración Pública - Global Law Press, Sevilla, 2012, pp. 28 y ss.; y PARejo Alfonso, Luciano, "Transformación y ¿reforma? del Derecho Administrativo en España", en Barnes, J. (ed.), Innovación y Reforma en el Derecho Administrativo, $2^{\mathrm{a}}$ ed., Instituto Nacional de Administración Pública - Global Law Press, Sevilla, 2012, pp. 393 y ss., con análisis de las consecuencias para el Estado y, señaladamente, para el Derecho administrativo.

7 Zagrebelsky, Gustavo, El derecho dúctil. Ley, derechos, justicia (traducción por Gascón, Marina), Trotta, Madrid, 2012, 11 ${ }^{\mathrm{a}}$ ed., p. 12.

${ }^{8} \mathrm{Al}$ respecto, vid. Schmidt-Assmann, Eberhard, La teoría general del derecho administrativo como sistema (traducción por Bacigalupo, Mariano et al), Instituto Nacional de Administración Pública y Marcial Pons, Madrid, 2003; y, del mismo autor, Schmidt-Assmann, Eberhard, "Cuestiones fundamentales sobre la reforma de la Teoría General del Derecho Administrativo. Necesidad de la innovación y presupuestos metodológicos", en Barnes, J. (ed.), Innovación y Reforma en el Derecho Administrativo, Global Law Press, Sevilla, 2012, 2ª ed.
} 
algunos de los presupuestos tradicionales del Derecho administrativo. A tal efecto, se analizan tres temas específicos: 1) el procedimiento administrativo y la pluralidad de valores e intereses; 2) los retos que los progresos científicotecnológicos le imponen al Derecho; y, 3) la construcción del Estado garante y regulador.

\section{EL DERECHO ADMINISTRATIVO EN TIEMPOS DE TRANSFORMA- CIONES COMO CONTEXTO: LA CIENCIA ADMINISTRATIVA COMO CIENCIA DIRECTIVA}

En concordancia con lo antes apuntado, cabe consignar que constituye un lugar común sostener que el Derecho administrativo se encuentra en proceso de cambios, particularmente por el influjo de la doctrina jurídico-pública alemana; de la llamada Escuela de Reforma del Derecho administrativo. ${ }^{9}$

Al respecto, conviene recordar que la concepción tradicional del Derecho administrativo, propia del Estado liberal, se basaba en: ${ }^{10}$ 1) que el legislador predetermina, con el mayor detalle posible, las actuaciones de la Administración (cuyo papel, entonces, se limitaba a la mera ejecución de los mandatos de aquél); ${ }^{11}$ 2) la preponderancia del acto administrativo ${ }^{12}$ -que relegaba a un papel segundario al procedimiento- ${ }^{13}$ en tanto producto por antonomasia de la Administración, lo que permitía centrar en dicha actuación el control judicial de ésta: ${ }^{14} \mathrm{y}, 3$ ) que, desde el punto de vista del

\footnotetext{
${ }^{9} \mathrm{Al}$ respecto, véanse los ya citados trabajos de Schmidt-Assmann, cit. (n. 8)

${ }^{10}$ En general, se sigue aquí a Schmidt-Assmann, “Cuestiones fundamentales...”, cit. (n. 8) p. 35.

${ }^{11}$ Pues, se exaltaba el modelo de "dominación legal" basado en el principio de legalidad y, por lo mismo, se perseguía el sometimiento de la Administración al "imperio de la ley", como garantía de que el Estado no interviniese en los ámbitos de autonomía y libertad individuales. CALvo García, Manuel, Transformaciones del Estado y del Derecho, Universidad Externado de Colombia, Bogotá, 2005, pp. 58-59.

${ }^{12}$ En la concepción del Estado Liberal, se otorgaba al acto administrativo un papel central, al ser éste el correlato de la sentencia dictada por los tribunales de justicia. MAYER, Otto, Derecho Administrativo Alemán. Parte General. Tomo I (traducción de la versión francesa de 1904 por Heredia, Horacio y Krotoschin, Ernesto), Ediciones Depalma, Buenos Aires, 1982, 2a ed., pp.147-148.

${ }^{13}$ De Otтo y PARdo, Ignacio, "Recensión al libro de Bocanegra, Raúl, 'El valor de las sentencias del Tribunal Constitucional”", Revista Española de Derecho Constitucional, 1982, n 6, año 2, p. 327.

${ }^{14}$ Malaret García, Elisenda, "Los Principios del procedimiento administrativo y el responsable del procedimiento", en Tornos Mas, J. (coord.), Administración Pública y Procedimiento Administrativo, Bosch, Barcelona, 1994, p. 302.
} 
principio de separación de poderes, la Administración se definía en forma negativa o residual, en cuanto no tiene naturaleza legislativa o judicial.

Tal concepción, no obstante, se encuentra cuestionada desde la década de los 80 del siglo pasado; ${ }^{15}$ objeciones que traen causa, entre otros factores, de la imposibilidad de la misma para hacer frente (y, por tanto, responder adecuadamente) a los desafíos que de suyo genera la evolución de las sociedades modernas, caracterizadas, fundamentalmente, por ${ }^{16}$ i) la compleja relación entre la dinámica propia del sistema económico imperante (singularmente, neocapitalista o neoliberal) y las exigencias de preservación de la naturaleza (debido a la toma de conciencia de la escasez de los recursos naturales o, en todo caso, por la sobreexplotación de éstos), dificultad que exige encontrar un justo equilibro entre ellas, de modo de fijar límites efectivos a la explotación del medio ambiente; ii) los avances de la ciencia y la tecnología, toda vez que los desarrollos en esa área han sido de tal porte, que la normal tensión estabilidad-cambio se ha desbalanceado en favor de esta última, aumentando, así, los niveles de incertidumbre y, por tanto, de preocupación por los riesgos en ella ínsitos; y, iii) la pluralidad de valores o intereses (muchas veces contrapuestos) en el seno de las sociedades democráticas, lo que produce una clara dificultad al momento, tanto de ponderar y definir una solución general (a través de una norma) ${ }^{17} \mathrm{o}$ específica (un acto administrativo), como de fijar valores comunes, siquiera mínimos, para la convivencia pacífica, esto es, el orden público.

En tal orden de consideraciones, se ha puesto de relieve ${ }^{18}$ que el Estado ha ido perdiendo paulatinamente su carácter de última o central

\footnotetext{
${ }^{15}$ Montero Cartes, Cristian, "Participación ciudadana, procedimiento administrativo y el deber de buena administración", Revista Española de Relaciones Internacionales, 2017, n 9, pp. 102 (disponible en línea: http://reri.difusionjuridica.es/index.php/RERI/article/view/122/99).

${ }^{16}$ En general, se siguen aquí algunas ideas de Parejo Alfonso, Luciano, Crisis y Renovación en el Derecho Público, Palestra, Lima, 2008, reimpr., pp. 13-14 y 57 y ss.

${ }^{17}$ Pues, como ha señalado HäBERLE, en el poder legislativo de lo que se trata es, principalmente, "de cuestiones de ponderación y de problemas de equilibrio entre intereses (...) a la hora de hablar del actual pluralismo de intereses". HäBErle, Peter, Pluralismo y Constitución. Estudios de Teoría Constitucional de la sociedad abierta (traducción y estudio preliminar de Mikunda-Franco), Tecnos, Madrid, 2002, p. 144.
}

${ }^{18}$ V. Parejo Alfonso, cit. (n. 16), pp. 13-14. 
instancia (monocéntrica) ${ }^{19}$ en la definición de las fuentes del Derecho ${ }^{20}$ y del tráfico social (se alude ahora a una "teoría policéntrica del Estado"21) por razón, tanto de la apertura hacia el exterior (señaladamente, por el influjo del Derecho internacional -como en materia de Derechos humanos- ${ }^{22}$ o el caso del proceso de integración europea -con la consiguiente exigencia de la transferencia de funciones y competencias desde los Estados miembros a la Unión Europea-), como de la descentralización territorial (en atención a las exigencias de que las decisiones relevantes para la vida social sean adoptadas a nivel regional o, incluso, local) y la funcional (al encomendar, en determinados ámbitos, la ejecución material de tareas públicas a entidades públicas independientes o a organizaciones sociales o, en general, a los privados).

Tales transformaciones han comportado (en forma explícita o solapada), entre otros efectos, una progresiva fragmentación de las tradicionales fuentes del derecho (por razón de la crisis del principio de jerarquía y la introducción de formas blandas de derecho o soft law, incluso de origen privado), y la imposición de modelos de estructura organizativa ajenos a la concepción clásica del principio de separación de los poderes (p. ej. las llamadas Autoridades Nacionales de Reglamentación o Regulación -ANR-).

Por las consideraciones descritas, la apuntada perspectiva tradicional ${ }^{23}$

\footnotetext{
${ }^{19}$ Como explica García-Pelayo, en los sistemas de "tipo monocéntrico", una sola organización central domina a las restantes, puesto que constituye la última y decisiva entidad que atiende las demandas y resuelve por sí misma el grado de intervención necesario y, por ello, el poder aparece condensado en esa organización central; a este sistema se opone el "tipo pluricéntrico", definido por que cada organización se sustenta por sí misma y opera en un ámbito protegido por el Derecho, pero, en todo caso, existe una red de recíproca de relaciones, con lo cual cada organización, actuando autónomamente, contribuye positiva o negativamente a la consecución de los objetivos comunes. García-Pelayo, Manuel, Las transformaciones del Estado contemporáneo, Alianza Editorial, Madrid, 2005, 2ª ed. (11ª reim.), pp. 114-116.

${ }^{20}$ Se pone de relieve que la ideología que afirma que el Estado tiene el monopolio en materia de fuentes jurídicas es "ajena" al actual Estado Constitucional (calificado como "Estado Constitucional Cooperativo"), pues éste se abre, en forma progresiva, a procedimientos jurídicos e interpretaciones elaboradas a nivel internacional o supraestatal. HäBERLE, cit. (n. 17), p. 288.

${ }^{21}$ BroHm, Winfried, "Administración y Jurisdicción Contencioso-Administrativa como mecanismos de regulación en un sistema policéntrico de producción del Derecho", Documentación Administrativa, 1993, n²34, p. 124. Pues en "las comunidades altamente complejas, como es el caso de la sociedad industrializada, sólo son regulables -de modo análogo al modelo cibernético de los conjuntos de reglasmediante el juego de una pluralidad de centros de decisión".

22 Como anticipara HäBerle, en el nuevo Estado Constitucional se produce una "apertura" a las vinculaciones internaciones, lo que incluso producirá "efectos ejecutivos inmediatos" en el ámbito interno del Estado (permeabilidad), especialmente, en lo relativo a los Derechos humanos. HäBERLE, cit. (n. 17), p. 295.

${ }^{23}$ Idea expresa por el autor en MonTero, cit. (n. 15), p. 102.
} 
(que cifraba la legitimación democrática de la Administración únicamente en la aplicación monolítica de la ley -al ser ésta sancionada por los representantes del pueblo y de ellos pasar el Gobierno y llegar a los órganos administrativos, como una "cadena ininterrumpida de legitimación" 24 o "correa de transmisión"25-) aparece como insuficiente para explicar la complejidad y variedad de las cuestiones abiertas al Derecho Público. ${ }^{26}$

En el contexto reseñado, la mencionada Escuela de Reforma alemana ha abogado por la reconstrucción del modelo del Derecho administrativo a través un conjunto de postulados que, sin pretender abandonar los presupuestos del enfoque tradicional, ${ }^{27}$ apuntan a afirmar que la ciencia del Derecho administrativo no se agota en la aplicación de la regla de derecho y su control judicial, ${ }^{28}$ sino que comprende, fundamentalmente, la eficacia de las normas: la efectividad del derecho y su capacidad real para la resolución de los problemas sociales. ${ }^{29}$

Ello, puesto que -suele olvidarse- el Derecho no es un fin en sí mismo, sino que constituye un instrumento que persigue su efectividad $y$, por tanto, el efecto de la configuración de la realidad: ${ }^{30}$ pues, “(s)i la función del Derecho es crear los incentivos adecuados para que los individuos se abstengan de realizar ciertas conductas consideradas perjudiciales para la comunidad y lleven a cabo otras socialmente valiosas, resulta de fundamental importancia verificar si las decisiones jurídicas producen efectivamente, en el terreno de los hechos, los resultados apetecidos". 31

Debe recordarse, en tal orden, que ya E. Forsthoff afirmaba que la "actividad administrativa se orienta siempre hacía algún resultado

\footnotetext{
${ }^{24}$ Schmidt-Assmann, "Cuestiones fundamentales...”, cit. (n. 8), p. 66.

${ }^{25}$ STEWART, Richard, "The reformation of American Administrative Law", Harvard Law Review, 1975, Vol. 88, No 8, p. 1675.

${ }^{26}$ En este punto, resulta de obligada lectura el texto de Parejo Alfonso, cit. (n. 16), el cual aborda provocativamente tales cuestiones.

${ }^{27}$ Schmidt-Assmann, “Cuestiones fundamentales...”, cit. (n. 8), p. 44.

${ }^{28}$ Montero Cartes, cit. (n. 15), p. 103.

${ }^{29}$ En esos términos lo expone Vosskuhle, Andreas, "Sobre el método del Derecho administrativo", en Barnes, J. (ed.), Innovación y Reforma en el Derecho Administrativo, Global Law Press, Sevilla, 2012, $2^{\mathrm{a}}$ ed., pp. 150-151.

${ }^{30}$ Montero, cit. (n. 15), p. 103; Parejo Alfonso, Transformación y ¿reforma?... cit. (n. 6), p. 55, y Parejo Alfonso, “Transformación y ¿reforma?...”, cit. (n. 6), p. 408.

${ }^{31}$ Doménech Pascual, Gabriel, "Principios jurídicos, proporcionalidad y análisis económico", en Ortega, L.; De La Sierra, S. (coords.), Ponderación y Derecho Administrativo, Marcial Pons, Madrid, 2009, p. 168.
} 
deseado", ${ }^{32}$ por lo no que no resulta extraño que se plantee por C. OfFE que para la Administración "se sitúan en primer lugar los resultados proyectados de la actividad administrativa (tareas o su realización) como criterios de evaluación de las actividades y decisiones internas administrativas (...) La eficacia no se define aquí ya por el seguimiento de reglas, sino por el logro de resultados o la realización de funciones (...) las premisas de la actividad administrativa ya no son reglas a cumplir a rajatabla, sino recursos a utilizar desde el punto de vista de su adecuación para ciertas tareas". ${ }^{33}$

Se entiende, así, que se predique por el profesor Schmidt-Assmann, que "no puede quedarse en la construcción dogmática de cada una de las instituciones y reglas. En consecuencia, al Derecho administrativo le interesan también las condiciones o presupuestos que hacen que una institución resulte eficaz o efectiva, que resulte operativa. Ello implica la inserción de cada una de esas instituciones en un contexto más amplio, a fin de analizar las relaciones e interacciones recíprocas, (...) la ciencia del Derecho administrativo ha de ser concebida como una ciencia de dirección, esto es, como una ciencia que aspira a dirigir con eficacia los procesos sociales". ${ }^{34}$

El Derecho, acorde con estos planteamientos, si bien no es el único medio de dirección (pues también lo son, el mercado, el personal y la organización), tiene atribuido un lugar de privilegio en la dirección de los procesos sociales, debiendo sus efectos, en todo caso, considerarse en relación con el resto de los medios, de forma de mejorar la eficacia de la acción. ${ }^{35}$ Para cumplir sus cometidos, debe recurrir a los más diversos instrumentos de dirección (autorizaciones, incentivos, fomento, programas legales de carácter material y de cumplimiento; cuestiones de organización y procedimientos, sanciones, etc.), todos los cuales apuntan, en definitiva, a la construcción de una estructura regulatoria. ${ }^{36}$

\footnotetext{
${ }^{32}$ Forsthoff, Ernst, Tratado de Derecho Administrativo (traducción de la $5^{\text {a }}$ edición alemana por Legaz Lacambra et al.), Instituto de Estudios Públicos, Madrid, 1985, p. 391.

${ }^{33}$ El autor plantea que se trata del modelo propio del Estado Social en oposición al modelo burocrático racional de Administración de M. Weber, en que lo relevante era el cumplimiento de las normas. OfFE, Claus, Partidos políticos y nuevos movimientos sociales (traducción de Gutiérrez, Juan), Editorial Sistema, Madrid, 1988, p. 12.

${ }^{34}$ Schmidt-Assmann, "Cuestiones fundamentales...”, cit. (n. 8), pp. 43 y ss.; y Schmidt-Assmann,

"La teoría general...", cit. (n. 8), pp. 28 y ss.

${ }^{35}$ Schmidt-Assmann, “Cuestiones fundamentales...”, cit. (n. 8), p. 46.

36 Ídem, pp. 48-51.
} 
En esa línea, como ha expuesto SchmidT-ASSMAnN, ${ }^{37}$ resulta fundamental modificar la concepción tradicional, pasando de i) la perspectiva del control, a la de la acción administrativa (por razón de que el objeto de la ciencia administrativa no es tanto -o no únicamente- su mero control, cuanto la racionalización de la acción administrativa y la garantía de su efectividad); ii) la "dogmática de la ejecución, a la Administración dirigida por la Ley" (pues, debido a la imposibilidad de que el legislador se anticipe y reproduzca con precisión la entera realidad que pretende disciplinar, la ley recurre a conceptos legales abiertos; cláusulas y mandatos de ponderación, y a la regulación a través de la fijación de fines y objetivos, cuya precisión el legislador descarga en la Administración); y, iii) el "Derecho administrativo prestacional, al Derecho Administrativo de garantía" (en tanto que lo que compete a la Administración es garantizar el resultado, la realización de las actividades administrativas, sin que se precise cómo, ni quién, por lo que, salvo norma expresa, su ejecución material puede quedar entregada a la propia sociedad, debiendo el Estado crear el marco jurídico, las instituciones y los procedimientos adecuados a tal efecto).

En tal sentido, la posición y papel de la Administración no se explican por la mera ejecución de los dictados del legislador; más bien "la ley y el Derecho dirigen la actividad administrativa", ${ }^{38}$ pues, como bien se ha expuesto, 39 en "presencia de objetivos sustanciales de amplio alcance" -cuya realización exige una gran cantidad y variedad de valoraciones, que, en muchas situaciones, no son adoptadas con anterioridad por el legislador-, la ley únicamente precisa la autoridad, sus facultades $\mathrm{y}$, en su caso, el procedimiento que ha de seguirse para la adopción de la decisión, actuando, así, la Administración con "una específica autonomía instrumental", cuyos límites, resultan en muchas ocasiones imprecisos.

Como se advierte, se pretende sostener un claro cambio de paradigma que, no abandonando ni sustituyendo la imperiosa necesidad de preocupación por el control judicial, aboga por la centralidad ${ }^{40}$ del estudio

\footnotetext{
${ }^{37}$ Schmidt-Assmann, "Cuestiones fundamentales...", cit. (n. 8), pp. 87 y ss.

${ }^{38}$ Rodríguez De Santiago, José María, Metodología del Derecho administrativo. Reglas de racionalidad para la adopción y el control de la decisión administrativa, Marcial Pons, Madrid, 2016, p. 20. Tal predicamento se encuentra en Schmidt-Assmann, "La teoría general...", cit. (n. 8), pp. 212 y ss.

${ }^{39}$ Zagrebelsky, cit. (n. 7), p. 35.

${ }^{40}$ Como bien anota ZAgrebelsky, el "rasgo más notorio del Derecho Público actual no es la sustitución radical de las categorías tradicionales, sino su "pérdida de la posición central"'. ZAGREBELSKY, cit. (n. 7), p. 12.
} 
de la dirección de la acción administrativa y, por lo mismo, no en lo que la Administración no puede hacer, sino, justamente, en aquello que puede y, más aún, está llamada a ejecutar: la satisfacción del interés general. "(U)na metodología -afirma Rodríguez de Santiago- que centre el objeto de análisis en la aplicación judicial de la norma jurídico-administrativa necesariamente presta más atención a lo que la Administración no puede hacer (perspectiva negativa), que lo que (perspectiva positiva) debe hacer". ${ }^{41}$

En este punto, cabe destacar que los planteamientos aquí consignados resultan particularmente interesantes, toda vez que, en último término, apuntan a dar algún grado de orientación en un entorno en el que se observa ${ }^{42}$ una paradoja en torno a la clásica función de dirección y ordenación (policía) del Derecho, toda vez que mientras ésta aparece erosionada por la pérdida de la posibilidad de anticiparse a la configuración de la realidad, debido a las constantes transformaciones que, a escala mundial y nacional, se suceden en los diversos ámbitos de la vida social (particularmente, en las áreas de la seguridad, ${ }^{43}$ la economía y los progresos científico-tecnológicos), las cuales se definen por su capacidad de generar profundos e inmediatos cambios -en un contexto que ha sido calificado por DenNINGER como de "desorden global"-, ${ }^{44}$ al mismo tiempo y justamente por lo anterior, se ha producido un aumento progresivo de la necesidad de garantizar las condiciones mínimas para el libre desarrollo de la personalidad y el funcionamiento de la sociedad, con lo cual se advierte en forma aún más acuciante la necesidad que el Estado ofrezca respuestas a estos nuevos desafíos (exigiéndose, así, un reforzamiento de la actividad de dirección y control).

Por último, cabe señalar que entre los aspectos vinculados con la nueva ciencia del Derecho administrativo interesa destacar -sucintamentetres de ellos que se podrían relacionar con el objeto de nuestro estudio, a saber: el procedimiento administrativo y la pluralidad de valores e intereses; los retos que los progresos científico-tecnológicos le imponen al Derecho; $y$, la construcción del Estado garante y regulador.

\footnotetext{
${ }^{41}$ Rodríguez De Santiago, cit. (n. 38), p. 13.

42 En general, se siguen aquí algunas ideas de Parejo Alfonso, cit. (n. 16), pp. 16-19; Parejo Alfonso, Transformación y ¿reforma?... cit. (n. 6), pp. 28-32, y PAREJo Alfonso, "Transformación y ¿reforma?...”, cit. (n. 6), pp. 393-396.

${ }^{43}$ V. supra.

${ }^{44}$ Denninger, Erhard, "Derecho en "desorden” global. Sobre los efectos de la globalización”, Anuario Iberoamericano de Justicia Constitucional, 2004, n 8 , pp. 117 y ss.
} 


\subsection{Procedimiento administrativo y pluralidad de valores e intereses ${ }^{45}$}

En torno a la idea de la ciencia del Derecho administrativo como ciencia de dirección eficaz de los procesos sociales, se han destacado, entre otros, los aspectos procedimentales de la legitimidad democrática, a través de la participación de los grupos sociales, bajo su propia responsabilidad, en la ordenación de los asuntos que a ellos les afecten.$^{46}$ Conforme a tal postulado, la Administración operaría "en modo cooperativo", ${ }^{47}$ buscando la cooperación del público en general, y del sector privado, erigiéndose el procedimiento en un "foro", ${ }^{48}$ en el que se puede hallar la respuesta más adecuada para la satisfacción general y en el cual los derechos fundamentales tienen un rol protagónico, ${ }^{49}$ abogándose por una "reconstrucción, en el marco de la teoría de la acción administrativa, de dos elementos fundamentales, tales como la participación del público en general (y no sólo de los interesados) y la articulación de los intereses plurales y libres". ${ }^{50}$

En este punto, es necesario destacar que, si bien el procedimiento administrativo y el proceso judicial son especies del género de procedimientos jurídicos ${ }^{51}$ no obstante ambos presentan diferencias significativas,

\footnotetext{
${ }^{45}$ En este acápite, se siguen algunas ideas ya expresadas por el autor de este trabajo de investigación en Montero, cit. (n. 15), pp. 103 y ss.

${ }^{46}$ Schmidt-Assmann, "Cuestiones fundamentales...”, cit. (n. 8), pp. 43 y ss.

${ }^{47}$ Barnes, Javier, "Algunas respuestas del Derecho Administrativo Contemporáneo ante las nuevas formas de regulación: Fuentes, alianzas con el Derecho Privado, Procedimientos de Tercera Generación", en Barnes, J. (ed.), Innovación y Reforma en el Derecho Administrativo, Global Law Press, Sevilla, 2012, 2a ed., p. 341.

${ }^{48}$ Ibídem, p. 342.

${ }^{49}$ Así, este nuevo entendimiento destaca la "doble naturaleza de la relación jurídico-administrativa" entre el ciudadano y la Administración: por un lado, por "la dimensión jurídico-material determinada por los derechos fundamentales, es decir, la posición subjetiva del ciudadano" y, por otro, "la dimensión procesal o de garantía de participación y defensa del ciudadano que se concreta en la forma de procedimiento administrativo y proceso judicial". V. PAREJo Alfonso, Luciano, La vigilancia y la supervisión administrativas. Un ensayo de su construcción como relación jurídica, Tirant Lo Blanch, Valencia, 2016, p. 137.

${ }^{50}$ Schmidt-Assmann, “Cuestiones fundamentales...”, cit. (n. 8), p. 72.

${ }^{51}$ Cierco SeIra, César, La participación de los interesados en el procedimiento administrativo, Publicaciones del Real Colegio de España, Bolonia, 2002, p. 31. No obstante, actualmente se matiza en cuanto a que tal idea es aceptable (ambos son especies dentro de una misma categoría), en tanto que, reconociendo que en el procedimiento administrativo también se crean normas (al ejercer la discrecionalidad -puesto que la Administración en el Estado social de Derecho está configurada para que, dentro de los márgenes que le atribuye la ley, elija y proteja los interés públicos relevantes y, por lo mismo, su diseño institucional persigue que aquélla pueda acceder a la mayor cantidad posible de información-), en los dos "la ley, si exige la aplicación de normas, está obligando (sic) a que el
} 
señaladamente, en su objeto: pues, en efecto, mientras el proceso judicial tiene por único objeto la protección o garantía de los derechos e intereses de las partes, el administrativo "persigue una doble finalidad: la ordenación, disciplina y limitación del poder, al tiempo que la eficacia y efectividad de la acción administrativa". ${ }^{52}$

Es, justamente, el énfasis exclusivo en la finalidad defensiva del procedimiento administrativo el que ha limitado notablemente las posibilidades de concebir a éste como cause para la expresión de los intereses de los ciudadanos. Pues, en efecto, dicho enfoque, en el contexto de una sociedad tan plural y heterogénea, no permite tener claridad -debido a su parcialidad- que la participación contribuye a la calidad y al acierto en la determinación del interés general en la situación respectiva. ${ }^{53}$

Por ello, la atención no puede seguir centrándose sólo en el estudio de la función defensiva -vinculada a la limitación y, por tanto, a las garantías de los sujetos intervinientes-, toda vez que el Derecho administrativo no persigue únicamente ni se agota en la protección de las partes directamente relacionadas con la decisión específica de que se trate, dado que en la sociedad actual existe una pluralidad de actores implicados ${ }^{54} \mathrm{y}$, por lo mismo, un conjunto variopinto de intereses en juego -muchas veces contrapuestos-, que deben ser ponderados por la Administración al momento de resolver: como bien expresó M. S. Giannini, que el procedimiento es la forma de la función administrativa significa que permite ordenar los diversos intereses involucrados, residiendo en ello su caracterización; constituye una secuencia ordenada de actos para la definición y resolución de una pluralidad de intereses, privados y públicos, en juego..$^{55}$

procedimiento (administrativo o judicial) se apoye en la razón para buscar la verdad del hecho concreto correspondiente al hecho abstracto." Medina AlCOz, Luis, "Los hechos en el Derecho administrativo. Una aproximación", Revista Española de Derecho Administrativo, 2016, n 177, pp. 141-143.

${ }^{52}$ Schmidt-Assmann, "La teoría general...", cit. (n. 8), p. 26.

${ }^{53}$ En un sentido similar, en el ámbito de la Unión Europea, v. Nieto Garrido, Eva; Martín Delgado, Isaac, Derecho administrativo europeo en el tratado de Lisboa, Marcial Pons, Madrid, 2010, pp. 194195.

54 "El Derecho de la UE en materia de procedimientos administrativos también se caracteriza por (...) (la) pluralidad de los actores implicados". Mir, O.; Hofmann, H.; Schneider, J.P.; Ziller, J. (dirs.), Código ReNEUAL de procedimiento administrativo de la Unión Europea, Instituto Nacional de Administración Pública, Madrid, 2015, p. 68.

${ }_{55}$ Giannini, Massimo Severo, Istituzioni di Diritto Amministrativo (segunda edición corregida por Mirabelli Centurione), Giuffrè Editore, Milan, 2000, pp. 271-273. 
En este sentido, debe consignarse que en las sociedades plurales ${ }^{56}$ el interés genera ${ }^{57}$ no es unívoco, ni tampoco determinado necesariamente por el legislador, sino que éste descarga, en forma usual, su precisión en la Administración, la que deber conocer y ponderar los diversos intereses privados y públicos de qué está compuesto aquél, a objeto de lograr el consenso y la aceptación de parte de los ciudadanos. Pues, "si se acepta que la Constitución -señala Medina AlCoz- es un marco flexible, relativamente neutral y abierto a múltiples ideologías, hay que convenir que en buena medida los fines e intereses merecedores de protección son muchísimas veces los que quieran seleccionar el legislador y la Administración". ${ }^{58}$

En otros términos, la acusada imposibilidad para el legislador de definir con anterioridad el concepto de interés general, producto de la enorme complejidad que supone la intervención en materias tan diversas, tales como el medio ambiente, ${ }^{59}$ la ordenación del territorio, el urbanismo, comunicaciones, consumo, etc., hace que resulte muy difícil que en sede legislativa se delimite per se la actuación que debe seguir la Administración. ${ }^{60}$

En suma, y como consigna Schmidt-Assmann, el procedimiento persigue, entre otras funciones, proporcionar a la Administración las bases correctas para una acertada toma de decisiones, la puesta en manifiesto de los intereses de un amplio grupo de sujetos y estimular la participación. ${ }^{61}$

56 "El carácter plural y abierto del sistema de valores europeo, obliga a descartar cualquier tipo de hegemonía o, en el peor de los casos, de una 'tiranía de valores' por parte de cualquier cultura nacional de Europa". Pérez Luño, Antonio, Nuevos retos del Estado Constitucional: Valores, derechos y garantías, Cuadernos de la Cátedra de Democracia y Derechos Humanos N² 2, Universidad de Alcalá de Henares, Madrid, 2010, p. 51.

${ }^{57}$ Se empleará aquí el concepto de interés general dado que, si bien en el pasado se empleaba la expresión interés público, en el marco de un Estado democrático de Derecho el interés al que debe someterse la Administración es al de la comunidad, el de la sociedad en su conjunto, y no el de la propia institución o sus agentes, sino el de los ciudadanos. "El principio de participación y el principio de centralidad del ser humano -afirma Rodríguez-Arana- me parece que reclama un entendimiento más amplio y abierto que el estricto y riguroso del interés público, hasta ahora en sentido más extendido". Rodríguez-Arana, Jaime, Derecho Administrativo y Derechos Fundamentales, Global Law Press, Editorial Derecho Global, Instituto Nacional de Administración Pública, Sevilla, 2015, p. 209.

${ }^{58}$ Medina Alcoz, cit. (n. 51), p. 140.

${ }^{59}$ El 17 de febrero de 2005 se aprobó el Convenio de la Comisión Económica de las Naciones Unidas para Europa sobre "El acceso a la información, la participación del público en la toma de decisiones y el acceso a la justicia en asuntos ambientales", adoptado en la Conferencia Ministerial "Medio Ambiente para Europa", celebrada en Aarhus (Dinamarca), el 25 de junio de 1998 (más conocido como convenio Aarhus), cuyo artículo $1^{\circ}$ señala, entre sus objetivos, el de "la participación del público en la toma de decisiones".

${ }^{60}$ Montero, cit. (n. 15), p. 107.

${ }^{61}$ Schmidt-Assmann, La teoría general... cit. (n. 8), p. 373. 
Ahora bien, tal como hemos señalado ${ }^{62}$ constatado, así, que la función del procedimiento administrativo no se agota en la defensa de los derechos de las partes del procedimiento, ${ }^{63}$ sino que a través de este se pretende satisfacer y asegurar de mejor manera el interés general, ${ }^{64}$ deviene en imprescindible la ampliación por la ley de los márgenes de discrecionalidad ${ }^{65}$ que le atribuye a la Administración, de modo de habilitarla para efectuar una ponderación caso a caso de los diversos intereses involucrados en la específica actuación administrativa. ${ }^{66}$

Ello, toda vez que, siguiendo a Ponce Solé, ${ }^{67}$ en el mundo real el interés general no existe en forma aislada, sino que se inserta compuesto de diversos intereses, públicos y privados. Así, cuanto más amplia la elección, como el caso de la discrecionalidad de planeamiento, más crece el número de involucrados. Por ello, la elección final en qué consiste la decisión discrecional es el resultado de ponderación comparativa de diversos intereses en orden a perseguir la satisfacción del interés general establecido en el ordenamiento jurídico. De esta forma, “(e)l procedimiento administrativo constituye, por tanto, la sede en la que el interés público abstracto previsto en la ley pasará a especificarse, por medio una composición de todos los intereses involucrados, en el interés público concreto que habrá de informar la decisión finalmente adoptada", ${ }^{68}$ con lo cual, desde luego -y a diferencia de la concepción tradicional-, el procedimiento administrativo aparece cumpliendo un rol central en la construcción actual del Derecho administrativo.

Como puede advertirse, la virtualidad del procedimiento administrativo para operar como un mecanismo o técnica jurídica que permite a los

\footnotetext{
${ }^{62}$ Montero, cit. (n. 15), p. 107.

${ }^{63}$ García De Enterría, Eduardo; Fernández, Tomás Ramón, Curso de Derecho Administrativo, Civitas-Thomson-Aranza, Cizur Menor, 2013, 13 ed., Tomo II, p. 459.

${ }^{64}$ Como anota Medina Alcoz, "lo relevante en el procedimiento administrativo puede ser, no dirimir una controversia, sino asegurar la protección de los intereses generales que ha identificado y seleccionado el legislador". Medina Alcoz, cit. (n. 51), p. 145.

${ }^{65}$ De allí que también sea necesario distinguir diversos tipos de discrecionalidad -como técnica, de planificación, de gestión, entre otras- según se trate de potestades normativas, como reglamentaria o planificadora, o simplemente de ejecución. Santamaría Pastor, Juan A.; Parejo Alfonso, Luciano, Derecho Administrativo. La jurisprudencia del Tribunal Supremo, Centro de Estudios Ramón de Arce, Madrid, 1992, reimpresión, pp. 130-131.

${ }^{66}$ Cierco Seira, cit. (n. 51), p. 77.

${ }^{67}$ Ponce Solé, Juli, Deber de Buena Administración y Derecho al Procedimiento Administrativo debido. Las bases Constitucionales del Procedimiento Administrativo y el ejercicio de la discrecionalidad, Lex Nova, Valladolid, 2001, p. 83.

${ }^{68}$ Cierco Seira, cit. (n. 51), p. 78.
} 
ciudadanos, no sólo acercarse a las instituciones que los gobiernan, sino también hacer presente sus derechos o intereses legítimos apunta, en definitiva, a la participación ciudadana: ello exige que tal participación deba ser igualitaria ${ }^{69} \mathrm{y}$, por lo mismo, los valores e intereses involucrados deben ser ponderados en forma neutral por la Administración. ${ }^{70}$ En este orden, CIERCO SEIRA señala que la "democratización del procedimiento administrativo presenta la virtud de otorgar una habilitación directa de intervención del ciudadano en la gestación de la voluntad administrativa, evitando así las limitaciones que son inmanentes a los canales democráticos basados en el recurso indirecto a la representación". ${ }^{71}$

Tal proceso comporta la necesidad de ampliar la legitimación en el procedimiento administrativo de quién puede, por un lado, ser oído antes de adoptar una decisión y, por otro, ser consultado con anterioridad a la determinación ${ }^{72}$ del acto pertinente. ${ }^{73}$ En este punto, es dable recordar, siguiendo a FERnÁNDEZ GonzÁLEz, ${ }^{74}$ las calidades o títulos en virtud de las cuales se podría intervenir en el procedimiento: así, uti singulis, esto es, en razón de titularidad de intereses o derechos propios e individuales; uti cives, en razón de ciudadano; y uti socius, esto es, como portador de intereses genéricos, colectivos o difusos. Según la doctrina,${ }^{75}$ sólo estas dos últimas modalidades

\footnotetext{
${ }^{69}$ Pues, como ha destacado SHAPIRO, la igualdad en la participación se convierte en una de las igualdades positivas más importantes en la vida moderna, ante la dificultad de saber en cada caso cuáles son los intereses generales a servir. SHAPIRO, Martín, "Equality and Diversity", European Review of Public Law, 1999, Vol. 11, n² 2, p. 400.

${ }^{70}$ Así lo afirma, a propósito de las relaciones jurídicos-administrativas plurilaterales, SCHMIDT-AssmanN,

"La teoría general...", cit. (n. 8), p. 185.

${ }^{71}$ Cierco Seira, cit. (n. 51), p. 79.

${ }^{72}$ Montero, cit. (n. 15), p. 110.

73 “(L)os derechos procesales son extremadamente importantes, porque constituyen un medio a través del cual los particulares pueden obtener acceso al concreto sistema legal. En cualquier sistema de Derecho Administrativo, uno tiene puntos de acceso o puentes (...) Cualquier régimen de Derecho Administrativo ofrece normalmente dos puntos de acceso cruciales: las reglas procedimentales que determinan quién está legitimado para ser oído o para intervenir antes de que la decisión esté adoptada y quién debe ser consulado antes de la adopción un acto normativo (...) y existirán reglas que concreten quién puede plantear ante un Tribunal que el órgano decisor ha sobrepasado sus poderes". CRAIG, Paul, "Process Rigths in Adjudication and Rulemanking: Legal and Political Perfectives", en Ziller, J. (ed.), What's New European Administrative Law? EUI Working Paper, Florencia, 2005, p. 25 (documento disponible en línea: http://cadmus.eui.eu/bitstream/handle/1814/3330/law05-10.pdf).

${ }^{74}$ Fernández GonzÁlez, Paula, "La Participación en la Administración Pública como expresión de interés supraindividuales (colectivos y difusos): a propósito de la ley de Transparencia, acceso a la información y buen gobierno", Tesis Doctoral, Universidad Carlos III de Madrid, Madrid, 2015, p. 122 (documento disponible en línea: https://e-archivo.uc3m.es/handle/10016/21490).

${ }^{75}$ García De Enterría, Eduardo, "Principios y modalidades de participación ciudadana en la vida
} 
se pueden considerar como participación ciudadana propiamente tal.

Pues bien, tal como hemos apuntado en otra oportunidad, ${ }^{76}$ corresponde lograr la apertura del procedimiento administrativo, no únicamente a la parte afectada con una finalidad defensiva (como el uti singulis), sino también a otros interesados que pretenden hacer presente datos o elementos de juicio (ampliando, así, la legitimación a los uti cives o uti socius), de suerte que contribuyan y cooperen a que la Administración tenga una visión completa y real de los supuestos de hecho respecto de los cuales habrá de adoptar una decisión (concretizando, así, el abstracto interés general ${ }^{77}$ ), particularmente, en materias tales como el urbanismo, consumo, etc.

De este modo, la participación de los ciudadanos en los procedimientos de formación de decisiones discrecionales -en calidad de uti cives y uti socius-, aparece como un instrumento eficaz para encauzar las demandas sociales de la ciudadanía (que son, en definitiva, expresión de los diversos intereses supraindividuales). ${ }^{78}$

\subsection{El derecho como facilitador de la innovación y los riesgos en ella insitos: los retos que ésta le impone a aquél}

Como ha puesto de relieve Schmidt-Assmann, ${ }^{79}$ en tanto que el Derecho tiene atribuida una función de orientación "debe dispensar la

administrativa”, en Gómez-Ferrer Morant, Rafael (coord.), Libro homenaje al profesor José Luis Villar Palasí, Civitas, Madrid, 1989, pp. 441-442.

${ }^{76}$ Montero, cit. (n. 15), pp. 110-111.

${ }^{77}$ En este contexto, cierta doctrina afirma que el interés general es inmanente no trascendente a los intereses de los ciudadanos. Ponce Solé, Juli, "Ciencias sociales, Derecho Administrativo y buena gestión pública. De la lucha contra las inmunidades del poder a la batalla por un buen gobierno y una buena administración mediante un diálogo fructífero", Revista Gestión y Análisis de Políticas, Nueva Época, 2014, $\mathrm{N}^{\circ} 11$ (ene-jun), pp. 23-42.

${ }^{78}$ Montero, cit. (n. 15), p. 111. Pues “(1)a trascendencia de esta dimensión "procesual” de la participación ciudadana en los asuntos públicos no deja de afectar al ejercicio de la dirección política del conjunto de Administraciones Públicas, en especial cuando se trata de canalizar las demandas de los llamados "intereses difusos". La capacidad de presión de estos colectivos sociales, de composición indeterminada y grado diferentes de organización, hacia las instituciones políticas y entidades administrativas convierte a veces un trámite procesal como es el de la audiencias de los ciudadanos afectados por un acto o decisión administrativa, en herramienta clave de participación ciudadana, que puede llegar a condicionar la toma de decisiones efectiva en torno a cuestiones de considerable repercusión en el conjunto de la sociedad". Ruiz-Rico Ruiz, Gerardo, "El Derecho a una Buena Administración. Dimensiones Constitucional y Estatutaria", en Ávila Rodríguez, C.; Gutiérrez Rodríguez, F. (coords.), El Derecho a una buena administración y la ética pública, Tirant Lo Blanch, Valencia, 2011, p. 57.

${ }^{79}$ Schmidt-Assmann, “Cuestiones fundamentales...”, cit. (n. 8), p. 27. 
suficiente estabilidad y garantía a las expectativas sociales que surgen en el plano de las conductas y de las acciones de los diversos sujetos". Por lo mismo, "los principios de seguridad jurídica y de confianza legítima contribuyen" aquí a dicha estabilidad y, por tanto, resultan fundamentales para la construcción del Estado de Derecho.

A tales efectos, cabe recordar que, en las tradicionales sociedades industriales, como apunta GARCÍA-PELAYO, el principal factor de crecimiento era la innovación -esto es, la aplicación constante de las novedades técnicas al proceso productivo-, pero se consideraba que ello no era algo que ocurriera al azar, sino que un proceso definido a través de la institucionalidad (incluso, el Estado debía determinar los objetivos tecnológicos nacionales) ${ }^{80}$

Sin embargo, las permanentes demandas de la sociedad actual, como resultado de la dinámica en la mayor parte de los aspectos de la vida, la continua presión de la competencia y las interrelaciones globales y las cuestiones no resueltas del presente vivir y del futuro (ligados, entre otros, a los constantes riesgos que la innovación lleva ínsita, señaladamente, los propios de la evolución científico-técnica y del desarrollo de procedimientos nuevos) ${ }^{81}$ han relevado con toda claridad en la actualidad la incapacidad del Estado para anticiparse y, por tanto, planificar la entera innovación.

En este contexto, cabe consignar que, caracterizándose las sociedades modernas por ser extremadamente dinámicas $\mathrm{y}$, por lo mismo, crear o transformar constantemente las realidades sociales, se exige del Derecho la construcción de estructuras y técnicas que respondan eficazmente a los desafíos que tal fenómeno le impone: singularmente, la regulación de la innovación -por razón de los continuos avances científicos y tecnológicos- y los riesgos que ella conlleva.

La solución a estas cuestiones escapa, con mucho, al objeto del presente trabajo. Baste, por ello, dejar constancia brevemente de algún aporte doctrinal sobre ellas.

En esa línea, en relación a lo primero, esto es, a la regulación de la innovación, la doctrina ${ }^{82}$ ha advertido que, v. gr., los órganos reguladores

\footnotetext{
${ }^{80}$ García-Pelayo, cit. (n. 19), pp. 70-71.

${ }^{81}$ Cfr. Parejo Alfonso, Luciano, Estado y Derecho en proceso de cambio. Las nuevas funciones de regulación y garantía del Estado social de soberanía limitada, Tirant Lo Blanch, Valencia, 2016, p. 167.

${ }^{82}$ De La Quadra-Salcedo, Tomás, "El nuevo marco legal de las Telecomunicaciones: significado y perspectivas", en De La Quadra-Salcedo, T. (dir.); Vida Fernández, J. (coord.), Derecho de las Telecomunicaciones, Thomsom Reuters-Civitas, Cizur Menor, 2015, pp. 96-97.
} 
de sectores económicos con tendencia al monopolio, como ocurre en telecomunicaciones -dada la necesidad de efectuar una inversión inicial desmedida para construir la infraestructura en el mercado de las telecomunicaciones- ${ }^{83}$ tienen que forzar dicha tendencia para conseguir, artificialmente, que se apliquen las reglas del mercado ideal ${ }^{84}$ (de allí que se afirme que existe "regulación cuando no hay mercado"). ${ }^{85}$ Por tal motivo, en muchas ocasiones, cuando no existe con anterioridad, deben ir elaborando la regla al hilo de la intervención, acorde a las particulares circunstancias del caso concreto, debiendo, entonces, adaptarse continuamente a las exigencias que les demanda el mercado -en razón de los progresivos avances científicotecnológicos.

De allí, pues, que surjan naturales interrogantes: por vía ejemplar, algunosautoressostienenquelaregulacióndelmercadodetelecomunicaciones por una ANR (como la imposición de obligaciones de acceso a las Redes nuevas Generación ${ }^{86}$-redes de fibra óptica en sus diversas modalidades-), ${ }^{87}$ supone siempre una merma para la innovación; ${ }^{88}$ si ello es así, entonces ¿no procede imponer obligaciones?, ¿no debe regularse?; en general, ¿cómo

\footnotetext{
${ }^{83}$ Callol García, Pedro, "La garantía de acceso a las redes de telecomunicaciones como requisito esencial para la liberación del sector”, Revista de Administración Pública, 1999, n 149, p. 400.

${ }^{84}$ Según el profesor F. Moderne, en una determinada acepción de regulación se trata, en primer lugar, de abrir el mercado a la competencia, que antes estaba restringido a los monopolios públicos (o semipúblicos) y, después, de asegurar su fluidez (lucha contra la reconstitución de monopolios o contra los abusos de una posición dominante). Moderne, Franck, "Los usos de la Noción 'regulación' en el derecho positivo y en la doctrina jurídica de los Estados de la Unión Europea", en Marcou, G.; Moderne, F. (dirs.), Derecho de la Regulación. Los Servicios Públicos y la Integración Regional. Tomo I. Comparaciones y comentarios, Editorial Universidad del Rosario, Bogotá, 2009, p. 101.

${ }^{85}$ Betancor, Andrés, Regulación: Mito y Derecho. Desmontando el mito para controlar la actividad de los reguladores económicos, Thomsom Reuters-Civitas, Cizur Menor, 2010, p. 63.

${ }^{86}$ Bien se sabe que uno de los rasgos más acusados del sector de las telecomunicaciones lo constituye, sin duda alguna, su estructura de red, lo cual comporta, a los efectos que interesan, que para poder prestar el servicio respectivo resulta indispensable la utilización de instalaciones e infraestructura de la red, cuya titularidad tradicionalmente pertenecía al Estado, a través de alguna empresa pública que monopolizaba el mercado. Con la introducción de la libre competencia y el término del monopolio estatal (producto de la liberación y la privatización), la cuestión del acceso a las redes se tornó una absoluta necesidad para lograr una competencia efectiva. V. MuÑoz Machado, Santiago, "Fundamentos e instrumentos jurídicos de la regulación", en Muñoz, S.; Esteve, J. (dirs.), Derecho de la regulación económica, Vol. I, Fundamentos e Instituciones de la Regulación, Iustel, Madrid, 2009, pp. 223 y ss. ${ }^{87} \mathrm{~V}$., sobre cuestiones vinculadas, la interesante sentencia del TJUE, 3 de diciembre 2009, Comisión Europea c. República Federal de Alemania, asunto C-424/07.

${ }^{88}$ BaÑo León, José María, "Reserva de Administración y Derecho Comunitario", en Esplugues Mota, C.; Palao Moreno, G. (eds.); Panadés Fons, M. (coord.), Nuevas fronteras del Derecho de la Unión Europea. Liber amicorum. José Luis Iglesias Buhigues, Tirant Lo Blanch, Valencia, 2012, pp. 845-846.
} 
compatibilizar las exigencias de innovación con los requerimientos de la regulación? ${ }^{89}$

Al respecto, Parejo Alfonso plantea que el Derecho suele ser visto como un enemigo de la innovación, no obstante, también puede operar como un incentivo (ejemplo, las subvenciones) y hasta como amortiguador e, incluso, recurso (delimitando obligaciones y responsabilidades). Lo importante, según manifiesta, es que cree seguridad para todos y los defienda frente a los peligros. "Cuanto mayor sea el riesgo o peligro de descontrol de una innovación, tanto mayor es la demanda al Derecho". ${ }^{90}$

En tal sentido, puntualiza que el Derecho debe regular "lo nuevo antes de que sea conocido o realidad" y sin poder aludir, usualmente, a experiencias, menos aún sistemáticas y contrastadas, debiendo regular, no obstante, "la imprevisibilidad de las condiciones funcionales" y los efectos de las nuevas técnicas e invenciones. "Incertidumbre, imprevisibilidad e insusceptibilidad de planificación se constituyen así en acompañantes de un instrumento -el jurídico- que en su entendimiento tradicional, sin embargo, busca prioritariamente seguridad y presupone posibilidad de planificación". ${ }^{91}$

Tal planteamiento es particularmente interesante en lo relativo al ejemplo antes aludido, esto es, el mercado de las telecomunicaciones, toda vez que, como se ha apuntado, las redes de nueva generación no existían -y, en todo caso, están en constante desarrollo-, lo cual comporta, por consiguiente, la ausencia de normas concretas definidas con anterioridad, por lo que, en muchas ocasiones, las ANR deben ir elaborando la regla mientras interviene (en muchos casos, se encargan de configurar las reglas, y no de meramente subsumirlas), acorde a las particulares circunstancias del caso concreto, a fin de adaptarse a los requerimientos que les demanda dicho sector.

En consonancia con ello, debe explicitarse el fenómeno, subrayado por el profesor PAREJo AlFonso, de la continua "flexibilización del contenido preceptivo de las normas" (utilizando el concepto de "regulaciones

\footnotetext{
${ }^{89}$ Como ha expuesto el Abogado General M. Poiares, las intervenciones en instalaciones de titularidad privada, a través de la imposición por las ANR de la obligación de conceder acceso o de entablar las negociaciones entre empresas, deben ser proporcionales y han de venir realmente impuesta por la situación competitiva, puesto que la regulación conlleva la disminución de los incentivos para invertir en infraestructura e innovación. Poiares Maduro, Miguel, Conclusiones del Abogado General del TJUE, en el asunto en el que recayó la interesante sentencia de 3 de diciembre 2009, Comisión Europea c. República Federal de Alemania, asunto C-424/07, 2009, aps. 50-53.

${ }^{90}$ Parejo Alfonso, cit. (n. 81), pp. 167-168.

${ }^{91}$ Ibídem, p. 168.
} 
elásticas"), a consecuencia de la progresiva imposibilidad de anticipar el futuro, en razón de que la creciente complejidad y, por tanto, "incertidumbre de éste obliga a una cierta sustitución de la seguridad por una mera fiabilidad en beneficio de la apertura" hacia el futuro, consistiendo el mecanismo "en la formulación normativa abierta de los criterios" de ejecución por la Administración, "a fin de permitir soluciones adaptadas a la naturaleza de las cosas y el contexto social". ${ }^{2}$

En el contexto que se viene exponiendo, PAREJo Alfonso plantea que el principal reto hoy para el Derecho es la creación y el mantenimiento de las condiciones precisas para la innovación, a cuyo efecto el Derecho debe: ${ }^{93}$

1.- Operar abriendo, impulsando (o creando $^{94}$ ) y manteniendo el mercado, de ser ello necesario, para la viabilidad de específicas innovaciones, una de cuyas variantes sería la previsión -así como, en su caso, imposiciónde mecanismos de coordinación de agentes en el correspondiente mercado (p. ej., en los articulados en redes, para garantizar el acceso a éstas).

2.- Establecer "instituciones e infraestructuras idóneas" para que los destinatarios y usuarios de las innovaciones las acepten y confíen en ellas (p. ej., la llamada Administración electrónica).

3.- Generar "garantías que despejen suficientemente las incertidumbres que la fase de aplicación supone para los oferentes de innovaciones" ( $p$. ej., en materia de firma digital en las transacciones digitales o de provisión electrónica de servicios).

4.- Desarrollar los mecanismos y las limitaciones que "equilibren la orientación del proceso innovador en principio solo por criterios empresariales" (dado que, p. ej., las innovaciones deben ser sostenibles ambientalmente).

Siendo ello así, y habida cuenta de lo expuesto, el autor que venimos siguiendo afirma ${ }^{95}$ que el Derecho debe reunir dos condiciones fundamentales para cumplir con su cometido: primero, la apertura a la innovación, teniendo presente dos factores; a) los tiempos no son iguales en todos los ámbitos (modernización económica y técnica y generación de

\footnotetext{
${ }^{92}$ Dicho autor analiza este fenómeno como un ejemplo de las potencialidades de la innovación del Derecho actual. Parejo Alfonso, Transformación y ¿reforma?... cit. (n. 6), pp. 37-38, y Parejo Alfonso, “Tranformación y ¿reforma?...”, cit. (n. 6), p. 399.

${ }^{93}$ Parejo Alfonso, cit. (n. 81), p. 199.

${ }^{94}$ Esto se entronca con la creación de un mercado, que naturalmente tiende al monopolio -en este caso, de las telecomunicaciones- allí donde no existe.

${ }^{95}$ Parejo Alfonso, cit. (n. 81), p. 172.
} 
riesgos -p. ej. medioambientales- es rápido, en tanto que en lo social es más lento); b) en ambos se producen riesgos (medioambientales, de bienestar o sostenibilidad) y no existe "autosuficiencia correctora, requiriendo la intervención pública (sea para lograr una modernización ecológica, sea para lograr una determinada calidad de los procesos sociales)".

Y, en segundo lugar, el "Derecho -en tanto que medio, en el Estado social de Derecho para la calidad de vida en libertad- debe asegurar una innovación responsable", ${ }^{96}$ considerando las consecuencias de ésta en vistas del bien común, de forma tal que los efectos negativos no anulen los positivos. ${ }^{97}$

Ahora bien, en relación al segundo aspecto mencionado, vale decir, los riesgos ínsitos en la innovación, cabe destacar con $\mathrm{WAHL}^{98}$ que, al tradicional concepto de peligro (y de evitación de peligros), se suma ahora el de riesgo, el cual si bien exige, en un primer momento, determinar el "umbral material hasta el cual una conducta es admisible", luego requiere determinar las reglas del procedimiento y la competencia a través de las cuales se establece cómo llegar a un específico resultado.

En estos nuevos escenarios, para el cumplimiento de su función de control y seguridad, al Derecho no le basta, como ha puesto de relieve D. Grimm, con su tradicional arsenal de instrumentos (referidos a peligros inminentes, limitados y de alcance más o menos puntual e imputables a sujetos específicos), requiriéndose de nuevas técnicas que, en ausencia de experiencia previa, establezcan obligaciones siquiera genéricas destinadas a la prevención; pues, en efecto, en algunas ocasiones resulta imposible determinar, no sólo el causante preciso del daño o riesgo, sino que, incluso, su extensión temporal o espacial ${ }^{99}$ (en un contexto en que la magnitud de los riesgos ha llegado a niveles desconocidos, incluyendo, "la posibilidad de autodestrucción de la humanidad"). ${ }^{100}$

\footnotetext{
${ }^{96}$ Ibídem.

${ }^{97}$ A nuestro juicio, un ejemplo contrario a la innovación responsable es el caso de aquellas normativas que establecen como eximentes de responsabilidad el desconocimiento de los potenciales efectos dañinos de nuevos productos o tecnologías, puesto que ellas permiten que quienes lo generen se amparen en el desconocimiento, sin incentivar medidas de cautela, ni el conocimiento científico riguroso que, justamente, podría detectar anticipadamente los peligros. Esteve Pardo, José, Nueva Relación entre Estado y Sociedad. Aproximación al trasfondo de la crisis, Marcial Pons, Madrid, 2013, pp.158-159.

${ }^{98}$ WAHL, Rainer, Los últimos cincuenta años del Derecho administrativo alemán (traducción de la versión alemana de 2006 por Mardomingo, José C.), Marcial Pons, Madrid, 2013, pp. 115-116.

${ }^{99}$ Grimm, Dieter, Constitucionalismo y Derechos fundamentales, Trotta, Madrid, 2006, p. 191.

${ }^{100}$ Ibídem, p. 190.
} 
De aquí, pues, que se sostenga ${ }^{101}$ que la incertidumbre acerca de los desarrollos futuros es de tal envergadura que más que "sociedad del riesgo" nos encontramos ante una "sociedad del desconocimiento" (U. BECK), en la que existe, incluso, un riesgo específico: "a veces ni siquiera se sabe que no sabemos", lo que impone generar de modo voluntario nuevos conocimientos.

Siendo ello así, no se trata de la pretensión de descartar todos los riesgos (tarea en sí utópica en la actualidad), sino más bien, como ha apuntado recientemente ROJAS CALDERÓn, de elegir entre riesgos, debiendo los poderes públicos determinar, a lo menos, el riesgo que se acepta (risk assessment), la gestión del riesgo (risk management) y la responsabilidad por el riesgo (risk liability). ${ }^{102}$

Justamente, y a propósito de la gestión de riesgos, se puntualiza por RodRíguez DE SANTIAGO ${ }^{103}$ que la dirección normativa de la Administración se está "desmaterializando" (I. ApPEL), en tanto se aprecia un aumento de los niveles de incertidumbre y, por lo mismo, de inseguridad, lo cual se traduce en que el legislador decida no resolver la situación específica (señaladamente, en decisiones riesgosas), a través de la programación de su contenido, sino que se limite a crear al efecto el marco jurídico y las estructuras adecuadas, a fin de que sea la Administración la que, ulteriormente, resuelva sobre el particular.

Consecuente con ello, el procedimiento administrativo respectivo aparece cumpliendo un importante rol: como primera prioridad, opera como un mecanismo destinado a obtener toda la información y los medios para reducir al mínimo la inseguridad y, en último término, generar conocimiento nuevo.

En tal orden de ideas, se observa por la doctrina ${ }^{104}$ que diversas normativas imponen a la Administración la obligación de emitir pronunciamientos acerca de hipótesis futuras, debiendo ésta anticiparse y ponderar, en su caso, los riesgos y beneficios que resultan, v. gr., de autorizar o prohibir una actividad o producto: aún más, en muchas ocasiones, se exige a los órganos públicos

\footnotetext{
${ }^{101}$ Hoffmann-Riem, cit. (n. 1), p. 194.

102 Rojas Calderón, Christian, Riesgos y Derecho administrativo. Desde el control a la regulación, Der Ediciones, Santiago, 2019, pp. 81-83.

${ }^{103}$ Rodríguez De SAntiago, cit. (n. 38), pp. 20 y 53, notas 27 y 64, que cita a Apeel, Ivo, "Methodik des Umgangs mit Ungewissheit", en Schmidt-Aßmann, E.; Hoffmann-RIEM, W. (dirs.), Methoden der Verwaltungsrechtswissenschaft (Schriften zur Reform des Verwaltungsrechts Band 10), Nomos Verlagsgesellschaft, Baden-Baden, 2004, pp. 337 y 354.

${ }^{104}$ Medina Alcoz, cit. (n. 51), pp. 155-156.
} 
que adopten decisiones sin que las evaluaciones científico-técnicas despejen la incertidumbre de si el riesgo es o no real.

Así, por ejemplo, la Ley 29/2006, de 26 de julio -de garantías y uso racional de los medicamentos y productos-, dispone, en su artículo 10.1. c), en lo que interesa, que la AEMPS ${ }^{105}$ otorgará la autorización a un medicamento si, entre otras condiciones, éste es eficaz en las indicaciones terapéuticas para las que se ofrece, debiéndose apreciar, según el artículo 10.2., la evaluación de los efectos terapéuticos positivos del medicamento en relación con cualquier riesgo relacionado con la calidad, la seguridad y la eficacia del medicamento para la salud del paciente o la salud pública, entendido como relación beneficio/riesgo. ${ }^{106}$

Por fin, lo que está claro, en concordancia con la concepción del Derecho administrativo como ciencia de dirección, es que cuando de la "innovación se trata no sirve, al menos como medio principal, el Derecho clásico de intervención (por más que éste siga siendo indispensable, especialmente para la evitación de riesgos), porque las innovaciones no se pueden imponer y si solo posibilitar o facilitar". ${ }^{107}$

En el contexto apuntado, el desafío es, pues, desarrollar nuevas técnicas jurídicas o la rearticulación de las existentes, de forma tal que el orden jurídico opere como un instrumento de facilitación de la innovación, y no como un enemigo de la misma, toda vez que, como apunta HoffmannRIEM, corresponde al Derecho crear al efecto las condiciones que permitan, al mismo tiempo, aprovechar las nuevas oportunidades que se generan y conjugar, en la medida de lo posible, los riesgos que de ellas se derivan. ${ }^{108}$

\subsection{Notas sobre el Estado garante y regulador: algunos de sus aspectos fundamentales}

Como explica García-Pelayo, la construcción política-liberal se basaba en la estricta división y oposición entre el Estado y sociedad, los cuales se concebían como sistemas "con un alto grado de autonomía" (así, el Estado, en

\footnotetext{
${ }^{105}$ Agencia Española de Medicamentos y Productos Sanitarios.

${ }^{106}$ Así, acorde a la letra a) del artículo 20 de la misma Ley, la autorización será denegada cuando "la relación beneficio-riesgo no sea favorable".

${ }^{107}$ Parejo Alfonso, cit. (n. 81), p. 171.

${ }^{108}$ Hoffmann-RIEM, Wolfgang, "Innovaciones en la jurisprudencia del Tribunal Constitucional alemán, a propósito de la garantía de los derechos fundamentales en respuesta a los cambios que conducen a la sociedad de la información", Revista de Derecho Constitucional Europeo, 2014, n² 22, p. 124.
} 
general, se inhibía de intervenir frente a los problemas económicos y sociales de la sociedad) y con sus propios caracteres: el primero, definido por ser una organización racional, de estructura vertical, articulada sobre relaciones de supra y subordinación y, la segunda, por ser un "orden espontáneo" dotado de "racionalidad inmanente", expresado, en general, en leyes económicas y de otra índole, y sustentada sobre relaciones competitivas. Por el contrario, el Estado Social pretendía la superación de tal esquema, en cuanto "Estado y sociedad no son ya sistemas autónomos, autorregulados", sino sistemas fuertemente autorrelacionados entre sí a través de relaciones complejas -pues ambos forman parten de un metasistema y, por tanto, tienen cualidades y principios estructurales complementarios-, destacando la acción del Estado a través de la prestación, dirección y distribución de las prestaciones sociales. ${ }^{109}$

Pues bien, las antes reseñadas transformaciones sociales y económicas $\mathrm{y}$, por lo mismo, las nuevas exigencias al Derecho han comportado la modulación de la concepción de la relación entre el Estado y la sociedad, señaladamente y con mayor fuerza, en aquellos sectores en que tradicionalmente se configuraban como servicios públicos. Pues, en efecto, desde las últimas dos décadas del $\mathrm{S}$. XX, ${ }^{110}$ los procesos de liberalización $\mathrm{y}$ de privatización generaron en Europa profundas modificaciones en diversos ámbitos, destacando, en lo que aquí interesa, el tránsito desde un Estado prestador -y, por tanto, asegurador directo de la realización del servicio público- ${ }^{111}$ a otro que cumple una función de garante, velando por el comportamiento de los agentes que operan en los sectores regulados, de modo que respeten las normas de competencia, y observen los estándares requeridos para la satisfacción eficiente del encargo (dación de bienes y prestación de servicios) a ellos confiado. ${ }^{112}$

${ }^{109}$ García-Pelayo, cit. (n. 19), pp. 21 y ss. Añade el autor que en el Derecho constitucional liberal la sociedad y el Estado se relacionaban fundamentalmente a través de la legislación (de ahí que se aludiera al "Estado Legislativo"), pero la Ley era concebida como constitutio y no actio, esto es, como creador de orden de las acciones de los individuos, pero no como una acción en sí misma, como una intervención en los sucesos (p. 123). Asimismo, v., BroHM, cit. (n. 21), p. 116.

${ }^{110}$ Sobre la introducción progresiva de la competencia fomentada por la revolución tecnológica, a partir del denominado Libro Verde de 1987, v. Pedraza Córdova, Juanita, Competencia efectiva y servicios de interés económico. El caso de las telecomunicaciones, Tirant Lo Blanch, Valencia, 2014, pp. 161-162.

${ }^{111}$ Pues, como apunta García-Pelayo, el Estado Social, en esencia, se trata de un "Estado programador, planificador y prestador de amplios servicios sociales", el cual operaba en un contexto muy complejo, pero se consideraba que se podría superar las dificultades si se actuaba con eficacia, a través de los adecuados "elementos detectores y reguladores". García-Pelayo, cit. (n. 19), p. 49.

112 Muñoz Machado, cit. (n 86), pp. 17-18, y Darnaculleta I Gardella, María M., "La recepción y 
Consecuentemente con ello, la doctrina ${ }^{113}$ advierte una recomposición de la responsabilidad de los poderes públicos por razón del traslado de la prestación directa por el Estado en los sectores regulados al sometimiento de éstos a las reglas del libre mercado: ${ }^{114}$ así, como respuesta a los fenómenos apuntados, la doctrina jurídico-pública alemana ha acuñado diversos términos (denominados conceptos clave o puente ${ }^{115}$ ) que pretender explicar el tipo de Estado al que parece dirigirse, aludiéndose al «Estado directivo», «Estado regulador», «Estado abierto» y, destacadamente, al «Estado garante» (Gewährleistungsstaat). ${ }^{116}$

Según apunta HofFMAnN-RIEM, el Estado garante constituye una "reacción" frente al progresivo "desplazamiento en los Estados contemporáneos de la realización de tareas públicas a agentes privados", caracterizándose por la simultánea responsabilidad del Estado en cuanto a "garantizar que las tareas públicas sean satisfechas" acorde a la calidad prevista por la normativa, "también cuando su cumplimiento se haya transferido a manos privadas". 117

Como apunta Franzius, la nueva distribución entre Estado y sociedad "tiene como presupuesto basal el mecanismo adecuado para garantizar la opción de los resultados políticamente deseados $\mathrm{y}$, por tanto, que los actores privados observen los pertinentes estándares de calidad (desde el

desarrollo de los conceptos y fórmulas de la regulación. El debate en la República Federal Alemana”, en Muñoz Machado, S.; Esteve Pardo, J. (dirs.), Derecho de la regulación económica, Vol. I, Fundamentos e Instituciones de la Regulación, Iustel, Madrid, 2009, p. 351. En igual sentido, Esteve PARDo, José, "La recepción en la Europa continental del Derecho de la regulación de la economía (Regulierungsrecht. La sistemática de la doctrina alemana y sus sustanciales analogías con la recepción doctrinal en España. Crónica de libros)", Revista de Administración Pública, 2010, n 183, pp. 305-306.

113 Vid., Darnaculleta I Gardella, cit. (n. 112), p. 361, y Esteve Pardo, José, El Estado garante. Idea y realidad, Instituto Nacional de Administración Pública, Madrid, 2015, pp. 95-96.

${ }^{114}$ En todo caso, es importante precisar que estos planteamientos se predican, en general, para los llamadores sectores regulados o mercados regulados.

${ }^{115}$ Vosskuhle, cit. (n. 29), pp. 176-177. Según expone el autor, tales conceptos cumplen al menos 4 funciones: 1) "función comprensiva", al aproximar y especificar su respectivo objeto de interés y trabajo científico; 2) "función interpretativa explicativa", al permitir generar supraconceptos o ideas ordenadoras superiores y, así, utilizarlos argumentativamente en diversos contextos; 3 ) "función de trabajo en común o en red", en tanto constituyen la primera aproximación a conceptos poco maduros, que inspirar a otros a trabajar en ellos; y, 4) "función orientadora", pues dan las indicaciones que deberán contener las subsiguientes construcciones. "Por consiguiente, los conceptos-clave están llamados a la concreción y al desarrollo ulterior, no dan una respuesta unívoca, sino que muestran el camino que ha de seguir el pensamiento jurídico".

${ }^{116}$ Los menciona VosSKuHLe, cit. (n. 29), pp. 179-180, nota 230.

${ }^{117}$ Hoffmann-Riem, cit. (n 108), pp. 139-140, nota 51. 
punto de vista del bien común), lo que hace imposible que el proceso se entregue sin más a la dinámica de la autorregulación e impone, por ello, el acompañamiento de la descarga de la realización material de tareas y cometidos con un adecuado régimen de regulación y supervisión". ${ }^{118}$

Por ello, y tal como puntualiza Parejo Alfonso, en el contexto de cambios y consiguiente necesidad de adaptación, el Estado garante comporta la reafirmación de su responsabilidad última en la mantención y ordenación de las condiciones de la vida social, esto es, el bien común: lo que no impide ni excluye la posibilidad de que sea la propia sociedad la que, manifestada a través del mercado o las organizaciones sociales o, en fin, los ciudadanos en general, puedan ejecutar materialmente dichas tareas, sobre la base de la confianza en su "capacidad de autorregulación". La idea subyacente es, pues, que toda tarea materialmente estatal (administrativa) puede, en principio, ser entregada $-\mathrm{y}$, por tanto, ejecutada- por la sociedad misma, mediante la descarga material de las tareas en sujetos privados, siempre que se creen al efecto las adecuadas estructuras de garantía de efectiva prestación (resultado), pues tal descarga "activa de suyo la dimensión imperativa del poder estatal público (dirección, regulación, control y supervisión)". ${ }^{119}$

De aquí, entonces, la exigencia para el Estado de construir las estructuras regulatorias, vale decir, el marco jurídico, las instituciones y los procedimientos apropiados para que los privados satisfagan la prestación de que se trate, cuyo resultado debe ser garantizado por la Administración. En ese orden, Schmidt-AssmanN ${ }^{120}$ afirma que, junto con las tradicionales funciones de la "Administración prestacional" y la "Administración ordenadora", ha surgido la "Administración garantizadora de la prestación", cuyas principales notas radicarían, a su juicio, en i) que "la Administración y el sector privado actúan de consuno" para la satisfacción del interés general; ii) "la preservación de la racionalidad propia de ambos subsistemas" (lo que significa: salvaguardia de la neutralidad del Estado y

\footnotetext{
${ }^{118}$ FranziUs, Claudio, Der Gewährleistungsstaat, 2007, 39 pp. (artículo basado en una conferencia que ofreció, en Speyer, el día el 1.2.2007, en la Universidad Alemana de Ciencias Administrativas), citado por PAReJo Alfonso, cit. (n. 81), pp. $75-76$ (documento disponible en línea: http://userpage.fu-berlin. de/ europe/team/FranziusC/texts/gew\%E4hrleistungsstaat.pdf).

${ }^{119}$ Parejo Alfonso, cit. (n. 81), p. 65. En tal sentido, se señala que, para la consecución de los fines del Estado garante, los poderes públicos deben adoptar "medidas jurídicas que cubren la responsabilidad de la garantía y que se activan cuando el cumplimiento de las tareas por parte de los sujetos privados encargados de ellas resulta insatisfactorio". HofFMANN-RiEM, cit. (n. 108), pp. 139-140, nota 51.

120 Schmidt-Assmann, Innovación y Reforma ... cit. (n. 8), pp. 106-108.
} 
la espontaneidad de la sociedad ${ }^{121}$ ); iii) la flexibilidad de los acuerdos entre el Estado y la sociedad; iv) la necesidad de autocontrol y autovigilancia y, por tanto, la orientación permanente hacia la publicidad y transparencia; y, v) la "creación de las estructuras necesarias" para establecer un marco adecuado y los objetivos necesarios al "contexto de reglas en interacción, sin petrificarlas".

Ahora bien, como la confianza en la lógica del mercado y, en general, de la sociedad, no llega al nivel de que pueda realizar por sí solos la satisfacción del interés general, resulta imprescindible que la acción pública asegure la dirección de los procesos y la supervisión de los correspondientes resultados: ${ }^{122}$ de donde se sigue que la responsabilidad estatal no se volatiliza, ${ }^{123}$ ni tampoco se produce "un repliegue sin más del Estado". ${ }^{124}$ Por ello, es que estos nuevos postulados no comportan la desaparición del Estado Social, ni mucho menos una retirada total del Estado, sino una mera modulación del mismo, ${ }^{125}$ toda vez que la garantía de prestación se mantiene ${ }^{126}$ (resultado), pero su ejecución material, esto es, la realización de la tarea necesaria para cumplirla, se encarga directamente a los particulares ${ }^{127}$ (con lo cual se produce, en su caso, una sustitución de los clásicos instrumentos de intervención en nuevas formas de cooperación). ${ }^{128}$

${ }^{121}$ Lo que resulta relevante, pues como antes mencionamos, la espontaneidad es una de las características de la sociedad.

${ }^{122}$ Parejo Alfonso, cit. (n. 81), p. 69.

${ }^{123}$ Pues, en todo caso, no desaparecen "sus elementos públicos objetivos, definiendo el servicio universal como nueva técnica de servicio público." García Álvarez, Gerardo, "La Unión Europea como ‘Estado Regulador' y las Administraciones independientes", Revista de Administración Pública, 2014, n 194, p. 83. Asimismo, se ha afirmado que el retroceso del Estado no comporta la "renuncia a la prestación de las garantías de seguridad de los ciudadanos ni de los niveles de prestación de los servicios sociales." Darnaculleta I GARDELLA, cit. (n. 112), pp. 384-385.

${ }^{124}$ Parejo Alfonso, cit. (n. 81), p. 65. Según Muñoz Machado, el Estado Regulador no ha desplazado al Estado gestor, pues si bien los poderes públicos han dejado de actuar como empresarios en diversos sectores de la vida económica, ha conservado posiciones como i) propietario, ii) gestor de empresas industriales, y iii) responsable de servicios sociales. MuÑoz Machado, cit. (n. 86), pp. 110-111.

${ }^{125}$ En tal sentido, Parejo Alfonso, cit. (n. 81), pp. 60 y ss.

${ }^{126}$ Puesto que, en el Estado Social, el Estado "se responsabiliza de garantizar aquellas condiciones de la existencia individual que ni el individuo, ni la sociedad se pueden asegurar por sí mismos" -GARCíAPelayo, cit. (n. 19), p. 127- y, por lo mismo, lo que determina a dicho tipo de Estado es el derecho prestacional, según apunta HäBERLE, cit. (n. 17), p. 164.

${ }^{127}$ Como ya lo advertía García-Pelayo, en el supuesto de crisis, debe operar una transformación del sistema estatal, pues el Estado social apunta no tanto a distribuir cada vez más, sino a distribuir mejor, asegurando con ello la vigencia del sistema económico, el que, ante problemas de escasez, tenga la capacidad de administrar con eficacia y justicia. García-Pelayo, cit. (n. 19), pp. 81-82.

${ }^{128}$ Schmidt-Assmann, “La teoría general...”, cit. (n. 8), p. 37. 
En tal contexto, la nueva figura del Estado garante ha sido definida por Parejo Alfonso como "aquél que, sin sustituir, por simplemente modular, el Estado social y democrático de Derecho, se centra -conforme a correspondiente decisión en sede política- en garantizar, sin asumir por ello directamente la tarea, la ejecución de determinados cometidos (dación de bienes y prestación de servicios), la cual puede ser llevada a cabo, así, igualmente por sujetos privados (es decir: el mercado), organizaciones de interés social (tercer sector) o, incluso, los propios ciudadanos". ${ }^{29}$

Para este autor, la comprensión cabal de esta nueva categoría debe considerar que el Estado tiene responsabilidad de i) cumplimiento o ejecución, relativa al deber de garantizar la ejecución por quién corresponda de la tarea a él encomendada; ii) garantía, referida al deber de asegurar que esos cometidos se realizarán acorde a los estándares prefijados; $\mathrm{y}$, iii) financiación, alusiva al deber de sufragar económicamente la realización de las tareas en beneficio de los destinatarios. ${ }^{130}$

Desde luego, el predicamento aquí destacado trastoca la construcción tradicional de la Administración, en cuanto ésta, como se ha afirmado, ${ }^{131}$ dejar de ser "heteroprogramada" (hasta en los detalles) por la ley, para asumir la función de regular ella misma (en términos de "autoprogramación"132), en parte importante, la actuación de los actores sociales, debiendo, así, articular el programa de tareas y cometidos que materialmente deben ejecutar los actores sociales y supervisar su cumplimiento (lo cual exige, como hemos apuntado, la elaboración de las estructuras adecuadas a tal efecto); claro ejemplo de ello son las llamadas ANR. Como precisa Medida Alcoz, la Ley "(p)uede no programar agotadoramente la acción administrativa $\mathrm{y}$, por tanto, puede no asegurar al ciudadano un resultado específico (p. ej., la autorización solicitada)". ${ }^{133}$

En el contexto apuntado, se entiende que se afirme ${ }^{134}$ que los fenómenos de desregulación, privatización y liberalización de determinados sectores de la vida social (singularmente, los mercados regulados) y, por tanto, de irrupción de los actores sociales, constituyan, así, la causa eficiente

\footnotetext{
${ }^{129}$ Parejo Alfonso, cit. (n. 81), pp. 71-72.

130 Parejo Alfonso, cit. (n. 81), pp. 72-73.

131 Parejo Alfonso, cit. (n. 81), p. 70.

132 Parejo Alfonso, cit. (n. 16), p. 64.

${ }^{133}$ Medina Alcoz, cit. (n. 51), p. 133.

${ }^{134}$ En tal sentido, PArejo Alfonso, cit. (n. 81), p. 69.
} 
del surgimiento de una nueva función en íntima conexión con el Estado garante: la regulación. Pues la descarga por el poder público de la ejecución material de las tareas en la sociedad exige, al mismo tiempo, la sustitución de "las facultades dominicales por mecanismos jurídicos de regulación de la actividad y ponderación de intereses". ${ }^{135}$

Como advierte J. Montero PASCuAl, más allá del sentido tradicional que se le atribuye al concepto de regulación (comprensivo del régimen jurídico al que se halla sometido un determinado sector de la realidad social), últimamente tal expresión se ha venido utilizando, de modo vago e impreciso, para aludir a la intervención pública en los sectores regulados. ${ }^{136}$

Ahora bien, desde un punto de vista general, se destaca que la regulación opera como un "control prolongado y localizado" (SELZNICK), ${ }^{137}$ por lo cual no puede agotarse en la mera dictación de normas: requiere, pues, del ejercicio continuo y más o menos extensivo en el tiempo de un conjunto de potestades públicas (reglamentación, supervisión, sancionadoras, etc.), ${ }^{138}$ que apuntan a una específica actividad regulada.

De allí que A. OGus señale que la clave de un buen sistema regulatorio radique en dos dimensiones: de un lado, en los instrumentos elegidos para alcanzar el objetivo deseado (los que deben ser apropiados para responder a las necesidades sociales y económicas que lo justifican, considerando, además, su impacto previsible en la comunidad regulada) y, del otro, en una estructura regulatoria articulada sobre los procesos y procedimientos que apuntan a controlar determinados comportamientos. ${ }^{139}$

Desde esa perspectiva, se ha definido a la regulación como "la actividad de la administración consistente en el control continuo de un mercado mediante la imposición a sus operadores de obligaciones jurídicas proporcionales a propósitos de interés general objetivamente determinadas

${ }^{135}$ García Álvarez, cit. (n. 123), p. 83.

${ }^{136}$ Así, lo pone de relieve Montero Pascual, Juan José, "La actividad administrativa de regulación: definición y régimen jurídico", Revista Digital de Derecho Administrativo, 2014, n 12, p. 25. (documento disponible en línea: http://revistas.uexternado.edu.co/index.php/Deradm/article/ view/3993/4294).

${ }^{137}$ Agrega el autor que, dicho control es ejercitado por una agencia pública sobre actividades que son valoradas por la comunidad o, en otros términos, que son de relevancia social. SELzNICK, Philip, "Focusing Organizational Research on Regulation", en Noll, R. (ed.), Regulatory Policy and the Social Sciences, University of California Press, Berkeley, 1985, p. 363.

${ }^{138}$ Cfr. Muñoz Machado, cit. (n. 86), p. 111.

139 Ogus, Anthony, "Regulatory Institutions and Structures", Annals of Public and Cooperative Economics, 2002, n $73 / 4$, pp. 628 y 638. 
según la valoración que en un ámbito de extraordinaria discrecionalidad realiza la administración". ${ }^{140}$

Por otra parte, cabe destacar que, acorde al Diccionario de la Real Academia, regular significa "(a)justar el funcionamiento de un sistema a determinados fines"; ${ }^{141}$ en tanto, según el Diccionario de M. Moliner, regular implica "(h)acer que una cierta cosa se produzca con sujeción a una regla o uniformemente", ${ }^{142}$ de lo cual se advierte que el objeto de la regulación consistiría en la pretensión de que los destinarios de una regla ajusten su actuar a la misma, a fin de que se alcancen ciertos objetivos ofines fijados por los poderes públicos. ${ }^{143}$

En tal sentido, como precisa Parejo Alfonso, la regulación aparece como un instrumento para "influir -desde determinados criterios o reglas y ejerciendo potestades administrativas- en el comportamiento de sujetos en el contexto de situaciones y procesos y con el objetivo de conseguir ciertos efectos": de donde ella i) se relaciona con la ejecución de un determinado programa de política pública y ii) permite desplazar la atención en el acto administrativo a la eficacia de la acción administrativa y, por lo tanto, se vincula con la concepción de la ciencia administrativa como directiva de procesos sociales. ${ }^{144}$

La regulación es, entonces, un instrumento fundamental para garantizar que, en el contexto del Estado garante, se ejecutarán los cometidos (dación de bienes o prestación de servicios) que materialmente se confían a los particulares.

En ese orden de ideas, C. Berringer define, en un sentido estricto, a la regulación como "la influencia estatal en la conducta de las empresas que operan en el mercado a través de la fijación de deberes y prohibiciones que solamente pueden ser impuestas de forma imperativa por el Estado". ${ }^{145}$

Enseguida, formula ${ }^{146}$ algunas de sus notas características, destacando,

\footnotetext{
${ }^{140}$ Montero Pascual, cit. (n. 136), p. 27.

${ }^{141}$ Diccionario de la Lengua Española, Real Academia Española, 2001, 22 $2^{\mathrm{a}}$ ed., p. 1311, en su significado tercero.

${ }^{142}$ Moliner, María, Diccionario de uso del español. J-Z, Gredos, 2007, $3^{\text {a }}$ ed., p. 2532, en su significado primero.

${ }^{143}$ Cfr. Parejo Alfonso, cit. (n. 81), p. 142.

${ }^{144}$ Parejo Alfonso, cit. (n. 81), pp. 142-143.

${ }^{145}$ BerRIngER, Christian, Regulierung als Erscheinungsform der Wirtschaftsaufsicht, C.H. Beck, München, 2004, p. 115, citado por Darnaculleta I Gardella, cit. (n. 112), p. 365.

${ }^{146}$ Berringer, cit. (n. 145), citado por Parejo Alfonso, cit. (n. 81), pp. 147-155.
} 
en lo que aquí interesa:

1.- "La capacidad de influir efectivamente en la actuación de los agentes que operan en el sector o mercado correspondiente" (acceso a éste, modo de operar y salida o abandono de los mismos).

2.- "La articulación de la influencia en términos de ejercicio del poder público y, muy especialmente, de órdenes y prohibición cuya efectividad se asegura a través, entre otras técnicas, de la vigilancia y la supervisión" (1o cual comporta, entre otras consecuencias, que la actividad de regulación se inscribe, en cuanto imperativa, en la categoría de intervención administrativa, lo que excluye el recurso a instrumentos de dirección y control calificados como «blandos» o la autorregulación).

3.- "En cuanto ejercicio de poder público, la regulación es, por, definición, finalista, tiene necesariamente fines y objetivos determinados" (lo que, en último término, se reconduce a la satisfacción general).

Habida cuenta de lo expuesto y para cumplir con su cometido, no es de extrañar que se afirme ${ }^{147}$ que las normas del Estado regulador se configuren de una manera general, más basada en los principios, criterios y guías que en normas detalladas, caracterizándose por la vaguedad, lo cual deja (mediante un lenguaje basado en principios y criterios) un amplio campo de discrecionalidad. Ello se afincaría en la necesidad de que los preceptos de que se trate puedan adaptarse con facilidad a continuos cambios de circunstancias, resolviendo, con rapidez, los diversos problemas a los que, en forma diaria, se enfrenta el mercado. ${ }^{148}$

En ese orden, J. Montero Pascual entiende que, si bien la regulación tiene caracteres que la acercan a algunas técnicas tradicionales, ella se distingue, entre otras notas -como la alteridad, el control y la continuidad-, por la "discrecionalidad de la administración para imponer obligaciones a las empresas prestadoras de servicios de interés general". ${ }^{149}$

En todo caso, la doctrina ha advertido que i) aún no se ha construido un Derecho de la regulación como rama diferenciada del Derecho

\footnotetext{
147 Solanes Mullor, Juan, Administraciones independientes y Estado Regulador. El impacto de la Unión Europea en el Derecho Público Español, Congreso de Diputados, Madrid, 2016, pp. 91-92.

${ }^{148}$ GARCía ÁllVAREZ, cit. (n. 123) p. 10. Y añade que la orientación a la competencia es difícil de articular mediante normas abstractas y decisiones administrativas de carácter reglado, de mera aplicación del Derecho. Por el contrario, el Derecho de la competencia se caracteriza por reglas finalistas, cuya aplicación descansa en un análisis técnico y económico de cada mercado.

${ }^{149}$ Montero Pascual, cit. (n. 136), pp. 28 y ss. (En particular, p. 41).
} 
administrativo ${ }^{150}$ y ii) en todo caso, por razón de su propia "vocación universalista" 151 y su configuración, la función de regulación dificulta su encuadramiento en los conceptos y técnicas clásicas del Derecho administrativo (centradas en el caso concreto resuelto a través del acto administrativo y su revisión judicial), en las cuales se han descuidado "los efectos y las consecuencias de la actuación administrativa y, con ello, la dirección de procesos dirigidos a configurar la realidad". ${ }^{152}$

\section{CONSIDERACIONES FINALES}

Como puede advertirse, los predicamentos aquí expuestos pretenden, en última instancia, destacar que la satisfacción del interés general requiere también de la formulación (o reconstrucción) de técnicas jurídicoadministrativas que permitan la realización efectiva del interés general, a través de la acción administrativa, de la misma forma que ya existen aquellas que persiguen la defensa de los derechos individuales. ${ }^{153}$

Pues, en efecto, en tanto actualmente no se trata únicamente de limitar el ejercicio de los poderes públicos frente a injerencias o intervenciones antijurídicas en la esfera de los ciudadanos, sino también, e incluso principalmente, los peligros provenientes de los poderes privados que amenazan con igual o mayor intensidad el goce efectivo de los derechos fundamentales, ${ }^{154}$ el Derecho administrativo está llamado a ejercer un rol especialmente destacado, a través de la articulación de técnicas específicas que, junto con defender los derechos individuales, persigan el despliegue (y, por tanto, la realización efectiva) de los intereses individuales y colectivos. "Nos hallamos -afirma Schmitd-Assmann- ante situaciones en las que no se trata ya de encontrar un balance o contrapeso frente al ejercicio

\footnotetext{
${ }^{150}$ Parejo Alfonso, cit. (n. 81), p. 145.

${ }^{151}$ Darnaculleta i Gardella, cit. (n. 112), p. 353.

152 Parejo Alfonso, cit. (n. 81), p. 142.

153 “(E)n definitiva, de lo que se trata es de que el jurista, en cuanto técnico del Derecho, formule y ponga a disposición de la sociedad técnicas concretas que hagan viable la realización de los intereses colectivos y generales, de la misma manera que ahora existen ya para la defensa de los derechos individuales". Nieto García, Alejandro, "La vocación del Derecho Administrativo de nuestro tiempo", Revista de Administración Pública, 1975, n 76, p. 27.

${ }_{154}$ Bilbao Ubillos, Juan María, La eficacia de los derechos fundamentales frente a particulares. Análisis de la jurisprudencia del Tribunal Constitucional, Boletín Oficial del Estado, Centro de Estudios Políticos y Constitucionales, Madrid, 1997, p. 243.
} 
desproporcionado del poder público, sino, más bien, a la inversa: ante supuestos en los que la Administración habrá de contrarrestar la acción de los grandes grupos de poder". ${ }^{155}$

Por lo tanto, los tradicionales análisis centrados exclusivamente en la pura aplicación de derechos y garantías al momento del control judicial, desconocen (por su parcialidad) que toda actividad administrativa también persigue el contrarrestar la afectación al interés general derivable de la acción de los poderes privados y, por lo mismo, en el ejercicio de la misma no debe verse tanto una amenaza a la libertad individual y colectiva, cuanto un instrumento que, al menos, facilita su despliegue. ${ }^{156}$

Por ello, resulta primordial que las elaboraciones jurídicoadministrativas, primero e inexcusablemente -tal como enseña PAREJO Alfonso-, se inspiren "indudablemente en la recuperación de la idea de la Administración no como un mal necesario, sino como un instrumento positivo de regulación y configuración sociales, de aseguramiento de las condiciones básicas de la vida en colectividad, así como del objetivo de la articulación de un sistema administrativo capaz de cumplir con eficacia sus cometidos". .57

\footnotetext{
${ }^{155}$ Schmidt-Assmann, La teoría general ... cit. (n. 8), p. 24-25. Agrega el autor que, por lo mismo, resulta insuficiente la visión defensiva o judicial del poder administrativo, dado que la actividad administrativa va más allá de dispensar la "mejor garantía a favor de las situaciones jurídicas consolidadas ante la injerencia de los poderes públicos." De otro modo, "si se pretendiera que toda acción administrativa estuviera presidida por el postulado de la presunción general de libertad" (a favor de una concreta libertad, agregamos nosotros), no se entendería que i) el individuo se vincula con la comunidad y, por lo tanto, compete al Estado el deber de proteger a todos los ciudadanos y ii) al existir una diversidad de intereses -muchos de los cuales son contrapuestos- que se formulan ante la Administración, el Derecho administrativo debe procesar y ponderar a todos y encontrar una adecuada respuesta, sin que "la Constitución se halla decantado de una vez por todas en favor de unos intereses o libertades en cuestión en perjuicio de otros, es decir, sin que haya establecido en favor de quién ha de jugar la presunción o principio pro libertate" (p. 25).

${ }^{156}$ En ese sentido, se ha planteado que la Administración pública (public administration) no debe concebirse como algo "maligno", sino como una entidad positiva que debe ser bienvenida, toda vez que el Derecho administrativo no persigue únicamente detener las malas prácticas administrativas, sino que fomentar y facilitar las buenas -a través de su canalización y guía-; de donde i) no es el control judicial el mejor mecanismo para cumplir tal cometido (en tanto que los tribunales operan resolviendo asuntos concretos sobre la base de reglas específicas) y ii) su fin debe ser aumentar la libertad personal y colectiva, en cuyo despliegue no debe verse al Estado como una amenaza, sino como un medio, a lo menos, para facilitarla. Tomkins, Adam, "In Defence of the Political Constitution", Oxford Journal of Legal Studies, 2002, Vol. 22, No 1, pp. 158-159.

${ }^{157}$ Parejo Alfonso, cit. (n. 16), p. 82.
} 


\section{BIBLIOGRAFÍA CITADA}

a) Doctrina

ApeEL, Ivo, "Methodik des Umgangs mitUngewissheit", en Schmidt-Aßmann, E.; Hoffmann-Riem, W. (dirs.), Methoden der Verwaltungsrechtswissenschaft (Schriften zur Reform des Verwaltungsrechts Band 10), Nomos Verlagsgesellschaft, Baden-Baden, 2004.

BAÑo LeÓn, José María, "Reserva de Administración y Derecho Comunitario", en Esplugues Mota, C.; Palao Moreno, G. (eds.); Panadés Fons, M. (coord.), Nuevas fronteras del Derecho de la Unión Europea. Liber amicorum. José Luis Iglesias Buhigues, Tirant Lo Blanch, Valencia, 2012.

BARNES, Javier, "Algunas respuestas del Derecho Administrativo Contemporáneo ante las nuevas formas de regulación: Fuentes, alianzas con el Derecho Privado, Procedimientos de Tercera Generación", en Barnes, J. (ed.), Innovación y Reforma en el Derecho Administrativo, Global Law Press, Sevilla,

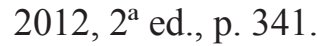

BERRINGER, Christian, Regulierung als Erscheinungsform der Wirtschaftsaufsicht, C.H. Beck, München, 2004.

Betancor, Andrés, Regulación: Mito y Derecho. Desmontando el mito para controlar la actividad de los reguladores económicos, Thomsom Reuters-Civitas, Cizur Menor, 2010.

Bilbao UbiLlos, Juan María, La eficacia de los derechos fundamentales frente a particulares. Análisis de la jurisprudencia del Tribunal Constitucional, Boletín Oficial del Estado, Centro de Estudios Políticos y Constitucionales, Madrid, 1997, p. 243.

BroHm, Winfried, "Administración y Jurisdicción ContenciosoAdministrativa como mecanismos de regulación en un sistema policéntrico de producción del Derecho", Documentación Administrativa, 1993, n 234.

Callol García, Pedro, "La garantía de acceso a las redes de telecomunicaciones como requisito esencial para la liberación del sector", Revista de Administración Pública, 1999, nº 149.

Calvo García, Manuel, "Transformaciones jurídicas y teoría del derecho", Anuario de Filosofía de Derecho, 2012, núm. 28, pp. 35 y ss.

Calvo García, Manuel, Transformaciones del Estado y del Derecho, Universidad Externado de Colombia, Bogotá, 2005, pp. 58-59.

Cierco SeIra, César, La participación de los interesados en el procedimiento administrativo, Publicaciones del Real Colegio de España, Bolonia, 2002.

Craig, Paul, "Process Rigths in Adjudication and Rulemanking: Legal and Political Perfectives", en Ziller, J. (ed.), What's New European Administrative Law? EUI Working Paper, Florencia, 2005, p. 25 (documento disponible en línea: http://cadmus.eui.eu/bitstream/handle/1814/3330/law05-10.pdf). 
Darnaculleta I Gardella, María M., "La recepción y desarrollo de los conceptos y fórmulas de la regulación. El debate en la República Federal Alemana", en Muñoz Machado, S.; Esteve Pardo, J. (dirs.), Derecho de la regulación económica, Vol. I, Fundamentos e Instituciones de la Regulación, Iustel, Madrid, 2009.

De LA Quadra-SAlcedo, Tomás, "El nuevo marco legal de las Telecomunicaciones: significado y perspectivas", en De La Quadra-Salcedo, T. (dir.); Vida Fernández, J. (coord.), Derecho de las Telecomunicaciones, Thomsom Reuters-Civitas, Cizur Menor, 2015.

De Отto y PArdo, Ignacio, "Recensión al libro de Bocanegra, Raúl, 'El valor de las sentencias del Tribunal Constitucional",, Revista Española de Derecho Constitucional, 1982, n 6, año 2, p. 327.

DenNinger, Erhard, "Derecho en "desorden" global. Sobre los efectos de la globalización", Anuario Iberoamericano de Justicia Constitucional, 2004, $\mathrm{n}^{\circ} 8$, pp. 117 y ss.

Doménech Pascual, Gabriel, "Principios jurídicos, proporcionalidad y análisis económico", en Ortega, L.; De La Sierra, S. (coords.), Ponderación y Derecho Administrativo, Marcial Pons, Madrid, 2009.

Esteve Pardo, José, “La recepción en la Europa continental del Derecho de la regulación de la economía (Regulierungsrecht. La sistemática de la doctrina alemana y sus sustanciales analogías con la recepción doctrinal en España. Crónica de libros)", Revista de Administración Pública, 2010, $\mathrm{n}^{\circ} 183$.

Esteve Pardo, José, Nueva Relación entre Estado y Sociedad. Aproximación al trasfondo de la crisis, Marcial Pons, Madrid, 2013.

Esteve Pardo, José, El Estado garante. Idea y realidad, Instituto Nacional de Administración Pública, Madrid, 2015.

Fernández GonzÁlez, Paula, "La Participación en la Administración Pública como expresión de interés supraindividuales (colectivos y difusos): a propósito de la ley de Transparencia, acceso a la información y buen gobierno", Tesis Doctoral, Universidad Carlos III de Madrid, Madrid, 2015, p. 122 (documento disponible en línea: https://e-archivo.uc3m.es/handle/10016/21490).

Forsthoff, Ernst, Tratado de Derecho Administrativo (traducción de la $5^{\mathrm{a}}$ edición alemana por Legaz Lacambra et al.), Instituto de Estudios Públicos, Madrid, 1985.

Franzius, Claudio, Documento "Der Gewährleistungsstaat", 2007, 39 pp. (artículo basado en conferencia: Speyer, 1.2.2007, Universidad Alemana de Ciencias Administrativas), documento disponible en línea: http:/userpage.fuberlin.de/ europe/team/FranziusC/texts/gew\%E4hrleistungsstaat.pdf.

García Álvarez, Gerardo, “La Unión Europea como 'Estado Regulador' y las Administraciones independientes", Revista de Administración Pública, 2014, n 194.

García De Enterría, Eduardo, "Principios y modalidades de participación ciudadana en la vida administrativa”, en GómEz-FERrer Morant, Rafael (coord.), 
Libro homenaje al profesor José Luis Villar Palasí, Civitas, Madrid, 1989, pp. 441-442.

García De Enterría, Eduardo; Fernández, Tomás Ramón, Curso de Derecho Administrativo, Civitas-Thomson-Aranza, Cizur Menor, 2013, 13 a ed., Tomo II, p. 459.

García-Pelayo, Manuel, Las transformaciones del Estado contemporáneo, Alianza Editorial, Madrid, 2005, $2^{\text {a }}$ ed. (11 ${ }^{\mathrm{a}}$ reimpr.).

Giannini, Massimo Severo, Istituzioni di Diritto Amministrativo (segunda edición corregida por Mirabelli Centurione), Giuffrè Editore, Milan, 2000, pp. 271-273.

GRIMM, Dieter, Constitucionalismo y Derechos fundamentales, Trotta, Madrid, 2006.

HÄBERle, Peter, Pluralismo y Constitución. Estudios de Teoría Constitucional de la sociedad abierta (traducción y estudio preliminar de Mikunda-Franco), Tecnos, Madrid, 2002, p. 144.

HofFMANN-RIEM, Wolfgang, "Jurisdicción. El procesamiento judicial de la incertidumbre sobre los desarrollos futuros", en Alguacil González-Aurioles, J.; Gutiérrez, I. (eds.), Constitución: norma y realidad. Teoría constitucional para Antonio López Pina, Marcial Pons, Madrid, 2014, p. 193.

Hoffmann-Riem, Wolfgang, "Innovaciones en la jurisprudencia del Tribunal Constitucional alemán, a propósito de la garantía de los derechos fundamentales en respuesta a los cambios que conducen a la sociedad de la información", Revista de Derecho Constitucional Europeo, 2014, n 22.

Malaret García, Elisenda, "Los Principios del procedimiento administrativo y el responsable del procedimiento", en Tornos Mas, J. (coord.), Administración Pública y Procedimiento Administrativo, Bosch, Barcelona, 1994, p. 302.

Mayer, Otto, Derecho Administrativo Alemán. Parte General. Tomo I (traducción de la versión francesa de 1904 por Heredia, Horacio y Krotoschin, Ernesto), Ediciones Depalma, Buenos Aires, 1982, 2a ed., pp.147-148.

Medina Alcoz, Luis, "Los hechos en el Derecho administrativo. Una aproximación”, Revista Española de Derecho Administrativo, 2016, n 177.

Mir, O.; Hofmann, H.; Schneider, J.P.; Ziller, J. (dirs.), Código ReNEUAL de procedimiento administrativo de la Unión Europea, Instituto Nacional de Administración Pública, Madrid, 2015.

Moderne, Franck, “Los usos de la Noción 'regulación' en el derecho positivo y en la doctrina jurídica de los Estados de la Unión Europea”, en Marcou, G.; Moderne, F. (dirs.), Derecho de la Regulación. Los Servicios Públicos y la Integración Regional. Tomo I. Comparaciones y comentarios, Editorial Universidad del Rosario, Bogotá, 2009.

Moliner, María, Diccionario de uso del español. J-Z, Gredos, 2007, $3^{\text {a }}$ ed.

Montero CARTEs, Cristian, "Participación ciudadana, procedimiento administrativo y el deber de buena administración", Revista Española de 
Relaciones Internacionales, 2017, $\mathrm{n}^{\circ}$ 9, pp. 102 (documento disponible en línea: http://reri.difusionjuridica.es/index.php/RERI/article/view/122/99).

Montero Pascual, Juan José, "La actividad administrativa de regulación: definición y régimen jurídico", Revista Digital de Derecho Administrativo, 2014, $\mathrm{n}^{\circ}$ 12, pp. 23-44 (documento disponible en línea: http://revistas.uexternado.edu.co/ index.php/Deradm/article/view/3993/4294).

MuÑoz Machado, Santiago, "Fundamentos e instrumentos jurídicos de la regulación”, en Muñoz, S.; Esteve, J. (dirs.), Derecho de la regulación económica, Vol. I, Fundamentos e Instituciones de la Regulación, Iustel, Madrid, 2009, pp. 223 y ss.

Nieto García, Alejandro, "La vocación del Derecho Administrativo de nuestro tiempo", Revista de Administración Pública, 1975, n 76, p. 27.

Nieto Garrido, Eva; Martín Delgado, Isaac, Derecho administrativo europeo en el tratado de Lisboa, Marcial Pons, Madrid, 2010, pp. 194-195.

Offe, Claus, Partidos políticos y nuevos movimientos sociales (traducción de Gutiérrez, Juan), Editorial Sistema, Madrid, 1988.

Ogus, Anthony, "Regulatory Institutions and Structures", Annals of Public and Cooperative Economics, 2002, $\mathrm{n}^{\circ} 73 / 4$.

Parejo Alfonso, Luciano, Crisis y Renovación en el Derecho Público, Palestra, Lima, 2008, reimpresión.

Parejo Alfonso, Luciano, Transformación y ¿reforma? del Derecho Administrativo en España, Instituto Nacional de Administración Pública - Global Law Press, Sevilla, 2012.

Parejo Alfonso, Luciano, "Transformación y ¿reforma? del Derecho Administrativo en España", en Barnes, J. (ed.), Innovación y Reforma en el Derecho Administrativo, $2^{\text {a }}$ ed., Instituto Nacional de Administración Pública - Global Law Press, Sevilla, 2012.

Parejo Alfonso, Luciano, La vigilancia y la supervisión administrativas. Un ensayo de su construcción como relación jurídica, Tirant Lo Blanch, Valencia, 2016.

Parejo Alfonso, Luciano, Estado y Derecho en proceso de cambio. Las nuevas funciones de regulación y garantía del Estado social de soberanía limitada, Tirant Lo Blanch, Valencia, 2016.

Pedraza Córdova, Juanita, Competencia efectiva y servicios de interés económico. El caso de las telecomunicaciones, Tirant Lo Blanch, Valencia, 2014.

Pérez LuÑo, Antonio, Nuevos retos del Estado Constitucional: Valores, derechos y garantías, Cuadernos de la Cátedra de Democracia y Derechos Humanos $\mathrm{N}^{\circ}$ 2, Universidad de Alcalá de Henares, Madrid, 2010.

Poiares Maduro, Miguel, Conclusiones del Abogado General del TJUE, en el asunto en el que recayó la sentencia del TJUE, 3 de diciembre 2009, Comisión Europea c. República Federal de Alemania, asunto C-424/07, 2009, aps. 50-53. 
Ponce SolÉ, Juli, Deber de Buena Administración y Derecho al Procedimiento Administrativo debido. Las bases Constitucionales del Procedimiento Administrativo y el ejercicio de la discrecionalidad, Lex Nova, Valladolid, 2001.

Ponce Solé, Juli, "Ciencias sociales, Derecho Administrativo y buena gestión pública. De la lucha contra las inmunidades del poder a la batalla por un buen gobierno y una buena administración mediante un diálogo fructífero", Revista Gestión y Análisis de Políticas, Nueva Época, 2014, N 11 (ene-jun), pp. 23-42.

RAE, Diccionario de la Lengua Española, Real Academia Española, 2001, $22^{\mathrm{a}}$ ed.

Rodríguez De SAntiago, José María, Metodología del Derecho administrativo. Reglas de racionalidad para la adopción y el control de la decisión administrativa, Marcial Pons, Madrid, 2016.

Rodríguez-Arana, Jaime, Derecho Administrativo y Derechos Fundamentales, Global Law Press, Editorial Derecho Global, Instituto Nacional de Administración Pública, Sevilla, 2015, p. 209.

Rojas Calderón, Christian, Riesgos y Derecho administrativo. Desde el control a la regulación, Der Ediciones, Santiago, 2019.

Ruiz-Rico Ruiz, Gerardo, "El Derecho a una Buena Administración. Dimensiones Constitucional y Estatutaria", en Ávila Rodríguez, C.; Gutiérrez Rodríguez, F. (coords.), El Derecho a una buena administración y la ética pública, Tirant Lo Blanch, Valencia, 2011.

Santamaría Pastor, Juan A.; Parejo Alfonso, Luciano, Derecho Administrativo. La jurisprudencia del Tribunal Supremo, Centro de Estudios Ramón de Arce, Madrid, 1992, reimpresión, pp. 130-131.

ShapIRo, Martín, "Equality and Diversity", European Review of Public Law, 1999, Vol. 11, n² 2, p. 400.

SChmidT-Assmann, Eberhard, La teoría general del derecho administrativo como sistema (traducción por Bacigalupo, Mariano et al), Instituto Nacional de Administración Pública y Marcial Pons, Madrid, 2003.

Schmidt-Assmann, Eberhard, "Cuestiones fundamentales sobre la reforma de la Teoría General del Derecho Administrativo. Necesidad de la innovación y presupuestos metodológicos", en Barnes, J. (ed.), Innovación y Reforma en el Derecho Administrativo, Global Law Press, Sevilla, 2012, $2^{\mathrm{a}}$ ed.

Selznick, Philip, "Focusing Organizational Research on Regulation", en Noll, R. (ed.), Regulatory Policy and the Social Sciences, University of California Press, Berkeley, 1985, p. 363 ss.

Solanes Mullor, Juan, Administraciones independientes y Estado Regulador. El impacto de la Unión Europea en el Derecho Público Español, Congreso de Diputados, Madrid, 2016.

Soper, Philip, Una teoría del Derecho (traducción por CARACCIOLO, Ricardo), Centro de Estudios Constitucionales, Madrid, 1993. 
STEWART, Richard, "The reformation of American Administrative Law", Harvard Law Review, 1975, Vol. 88, № 8, p. 1675 ss.

Tomkins, Adam, "In Defence of the Political Constitution", Oxford Journal of Legal Studies, 2002, Vol. 22, Nº 1 .

Twining, William, "Teoría General del Derecho", Anales de la Cátedra Francisco Suárez, 2005, Vol. 39, pp. 612 y ss.

Vosskuhle, Andreas, "Sobre el método del Derecho administrativo", en Barnes, J. (ed.), Innovación y Reforma en el Derecho Administrativo, Global Law Press, Sevilla, 2012, $2^{a}$ ed.

WAHL, Rainer, Los últimos cincuenta años del Derecho administrativo alemán (traducción de la versión alemana de 2006 por Mardomingo, José C.), Marcial Pons, Madrid, 2013.

Zagrebelsky, Gustavo, El derecho dúctil. Ley, derechos, justicia (traducción por GAscón, Marina), Trotta, Madrid, 2012, $11^{\mathrm{a}}$ ed.

b) Normativa

Convenio de la Comisión Económica de las Naciones Unidas para Europa sobre "El acceso a la información, la participación del público en la toma de decisiones y el acceso a la justicia en asuntos ambientales", adoptado en la Conferencia Ministerial "Medio Ambiente para Europa”, celebrada en Aarhus (Dinamarca), el 25 de junio de 1998 (más conocido como Convenio Aarhus).

c) Jurisprudencia

Tribunal de Justicia de la Unión Europea, sentencia de 3 de diciembre 2009, Comisión Europea c. República Federal de Alemania, asunto C-424/07. 